\title{
The Organization of the Motoneurons Innervating the Axial Musculature of Vertebrates. I. Goldfish (Carassius auratus) and Mudpuppies (Necturus maculosus)
}

\author{
JOSEPH R. FETCHO \\ Division of Biological Sciences, The University of Michigan, Ann Arbor, Michigan 48109
}

\begin{abstract}
The motoneurons innervating different regions of the myomeres in goldfish and mudpuppies were examined by applying HRP to the musculature or to branches of spinal nerves. In goldfish, the populations of motoneurons innervating epaxial or hypaxial muscle occupied similar positions in the motor column and had similar size distributions. There was no relationship between the size or location of a motoneuron in the motor column and the dorsoventral location of the muscle it innervated in the myomeres. Instead, different populations of motoneurons innervated the functionally different red and white musculature. The red muscle was innervated only by small motoneurons that occupied the ventral portion of the motor column. Their small axons passed lateral to the Mauthner axon in the cord, and most of them traveled in a separate branch of each spinal nerve that ran in the horizontal septum to the red muscle. The white muscle was innervated by a population of motoneurons that did not innervate red. They were large and they occupied a characteristic position in the extreme dorsal part of the motor column. Their large axons traveled medial to the Mauthner axon in the cord and entered branches of spinal nerves running deep in the epaxial or hypaxial muscle. The white muscle was probably also innervated by some smaller motoneurons similar to those innervating red; however, these may have been motoneurons whose axons ran through white muscle to reach other muscle. The large motoneurons innervating only white muscle are similar to the primary motoneurons identified in developmental studies in teleosts (Myers: Soc. Neurosci. Abstr. 9:848, '83); the smaller ones, innervating both red and white, are like secondary motoneurons. Therefore, in goldfish, motoneurons having different morphology and developmental history also innervate different regions in the myomeres.

The motor column in mudpuppies was, in general respects, similar to the column in goldfish. There were large primary motoneurons and small secondary ones. Though there were slight differences in the locations of motoneurons filled from nerves entering epaxial and hypaxial muscle, their distributions in the cord overlapped substantially.

The motor columns in these two anamniotes differ substantially from the motor columns in those amniotes that have been studied. In amniotes, the motoneurons innervating epaxial and hypaxial muscles are spatially segregated in the cord (Smith and Hollyday: $J$. Comp. Neurol 220:16-28, '83; Fetcho: J. Comp. Neurol. 249:551-563, '86). The absence of a comparable segregation in goldfish and mudpuppies implies that the medial motor column has undergone a major reorganization during the evolution of vertebrates.
\end{abstract}

Accepted February 14, 1986.

J.R. Fetcho's present address is the Division of Neurobiology, Department of Physiology, SUNY at Buffalo, Buffalo, NY 14214.

(C) 1986 ALAN R. LISS, INC. 
Key words: myomeres, spinal nerves, spinal cord, primary motoneurons, somatotopy

Nearly all of the musculature involved in generating the movements of vertebrates is evolutionarily derived from a simple primitive myomeric arrangement of axial muscles. This myomeric origin is evident during the development of living vertebrates as a rostrocaudal series of repeated muscle blocks, or myotomes, which appear early in embryonic development and ultimately differentiate to form the muscles in the adult. In some vertebrates these embryonic myotomes are retained in only a slightly modified form in the adult, as, for example, in the myomeres forming the axial musculature of many anamniotic vertebrates (Bone, '78; Johnston, '81). In others, the myotomes subdivide during development to contribute muscle to the paired fins or limbs or to form the many muscles in the rather complex axial musculature of amniotic vertebrates (Nishi, '38; Gasc, '81). The diversity in the anatomical arrangements of musculature among vertebrates indicates that the primitive myomeric musculature has been substantially reorganized during the evolution of their motor systems; however, it is less clear whether parallel modifications occurred in the organization of the central nervous system, which controls the muscles.

In this and the following paper I examine the arrangement of the motoneurons innervating the axial muscles in a few different vertebrates in order to evaluate what, if any, changes in the motor columns are correlated with differences in the anatomical and functional differentiation of the musculature. I have studied the motor columns in species representing extremes of the wide range of anatomical variation of axial musculature among vertebrates. This paper deals with the motor columns in goldfish (Carassius auratus) and mudpuppies (Necturus maculosus), two anamniotes having relatively simple myomeric musculature. In the following paper I examine the motor column in a snake (Nerodia fasciata pictiventris), an amniote in which the musculature is among the most complex in any vertebrate. The motor columns in the two anamniotes are very different from the motor column in the Florida water snake, and the differences imply that a major restructuring of the medial motor column occurred during the evolution of vertebrates. The nature of this restructuring has important implications for understanding the functional organization and evolution of motor systems.

The axial musculature of most anamniotic vertebrates is anatomically similar in two respects. First, the musculature is formed by a rostrocaudal series of repeating units, myomeres, which represent the relatively undifferentiated product of the myotomes in the embryo. Second, these myomeres are divided into superficial red and deep white muscle fibers (Sasaki, '74; Totland, '76a,b; Bone, '78). The two fiber types are functionally different; the red is specialized for generating slow sustained swimming, while the white is specialized for rapid or burst swimming (Bone, '78; Johnston, '81).

The major issues addressed in this paper center around the relationship between the organization of the medial motor column and these two basic structural features of the axial musculature of anamniotes. First, I examine whether there is a simple isomorphic relationship between the location of a motoneuron in the motor column and the location of the muscle it innervates in the myomere. Such a relationship might be expected, as recent studies of motoneurons innervating muscles derived embryonically and phylogenetically from myotomal muscle indicate there is often a simple topographic relationship between the position of a motoneuron and the position of the muscle it innervates in the embryo or the adult (Landmesser, '78a,b; Hollyday, '80; Smith and Hollyday, '83). Second, I examine whether any features of the organization of the motoneurons are related to the functional subdivision into red and white muscle.

\section{MATERIALS AND METHODS}

Goldfish (Carassius auratus, 80-170 mm standard length) and mudpuppies (Necturus maculosus, 180-220 mm snoutvent length) were obtained commercially (Grassy Forks Fisheries, Martinsville, IN, and Wards Biol. Supply, Rochester, NY) and maintained in well water. Both were anes. thetized in $0.1 \%$ aqueous tricaine methanesulfonate, and all surgical procedures, including sacrifice, were performed while they were anesthetized.

\section{Gross anatomy}

The branching patterns of spinal nerves were examined in both glutaraldehyde-fixed and freshly killed animals, which were sometimes stained with methylene blue or a dilute solution of $\mathrm{OsO}_{4}$.

\section{Semithin plastic sections}

Spinal cords or branches of spinal nerves were exposed and fixed in situ with a solution of $5 \%$ glutaraldehyde and $5 \%$ sucrose in phosphate buffer for 1 hour. The cords or nerves were postfixed in $\mathrm{OsO}_{4}$, and embedded in Epon. Semithin $(0.5$ or $1 \mu \mathrm{m})$ transverse sections were stained with toluidine blue and safranin-O (Davey and Bennett, ' 82 ).

\section{Electron microscopy}

Ultrathin sections (silver interference colors) stained with uranyl and lead ions were examined and photographed with a Philips 300 electron microscope.

\section{Horseradish peroxidase (HRP) labeling}

Goldfish. HRP was applied to various portions of the axial musculature by soaking a small pledget of Gelfoam (approximately a $2-\mathrm{mm}$ cube) in a $30-50 \%$ solution of HRP (in $7.5 \% \mathrm{NaCl}$ ) and implanting the pledget into or superficial to the musculature through a small slit in the skin, which was then closed with cyanoacrylate glue. In most cases, HRP was applied to axial musculature postanally on the rostral end of the tail.

To eliminate the problems associated with interanimal variability the sizes and positions of the motoneurons innervating different regions of the myomeres were compared between opposite sides of the spinal cord of individual fish in which HRP was applied at different places in the myomeres on opposite sides of the tail. Motoneurons filled by HRP applied to only one side of the tail were confined to the ipsilateral side of the spinal cord. Therefore, when muscle on both sides was labeled with HRP, HRP-filled motoneurons were unambiguously associated with the ipsilateral 
site of application. Muscle was labeled at four sites in each fish, two on each side of the tail, to maximize the number of labeled cells. Usually, one labeling site on each side of the fish was located at the rostral border of the anal fin and the other at its caudal border. After 4-7 days survival, the fish were anesthetized, transcardially perfused with saline and phosphate-buffered $4 \%$ glutaraldehyde, and their spinal cords were processed for HRP (see below).

In some experiments HRP was applied to individual branches of ventral roots on the tail by using one of two techniques. In the first, suggested by Dr. R.G. Northcutt, the fish were anesthetized and perfused with saline. The tail was removed, the nerve branches were cut, and the proximal end of a nerve was inserted in a small polyethyl ene well containing HRP. The tail was placed in a refrigerator $\left(3^{\circ} \mathrm{C}\right)$ overnight, and on the following day the cord was fixed for several hours by immersion in phosphate-buffered glutaraldehyde and then processed for HRP. Other fish were spinalized (under anesthesia) and nerves on the tail were cut and inserted into HRP-containing wells, as above. The fish were revived and placed on a sponge platform with their head in water so they could respire normally and their tail above water to avoid dilution or leakage of the HRP. The nerve was exposed to HRP for 4-5 hours, the HRP was removed, and the area was rinsed with saline. The wound was sealed with a piece of Parafilm attached to the skin with cyanoacrylate glue, and the fish were returned to their aquaria. After 2-7 days survival, the fish were perfused with saline and fixative, and their spinal cords were processed for HRP (see below).

Mudpuppies. Three different kinds of HRP-labeling experiments were performed with mudpuppies: HRP was applied to an entire severed ventral root $(N=5)$, to the proximal stump of transected branches of the dorsal $(\mathrm{N}=11)$ or ventral ramus $(N=14)$, or to the epaxial $(N=1)$ or hypaxial $(\mathrm{N}=2)$ musculature without intentionally damaging any spinal nerves.

To label an entire ventral root, the animals were transcardially perfused with amphibian Ringer's and decapitated, following which a proximal stump of a spinal nerve was labeled with HRP as in goldfish. The following day the spinal cord was removed, fixed by immersion in glutaraldehyde, and then processed for HRP.

To label branches of the dorsal or ventral rami, a slit was cut in the skin; a branch was located and transected; and an HRP-soaked pledget was placed onto the cut proximal end. The area was covered with petroleum jelly, and the skin was sutured shut. Most of these application sites were on the tail; two were on the trunk at approximately midbody. In a few cases motoneurons were labeled by inserting a piece of Gelfoam soaked in HRP into the musculature without cutting any branches of nerves in order to label motoneurons from terminals rather than severed axons. In sham labeling experiments designed to control for peroxi dase activity not related to the HRP, the same procedure was followed but the pledget was soaked in saline without HRP.

Initial experiments revealed that the motoneurons filled by HRP applied to branches of the dorsal or ventral ramus on only one side of the body were confined to the ipsilateral side of the cord. Therefore, in some experiments nerves on both sides of the body were exposed to HRP, and in these, the HRP-filled motoneurons were unambiguously associated with the ipsilateral labeling sites.

Following the application of HRP, the mudpuppies were maintained in aquaria for 3 days to 4 weeks and then were perfused first with amphibian Ringer's and then with glutaraldehyde. The spinal cord and dorsal and ventral rami of labeled spinal nerves were processed for HRP.

\section{Processing of spinal cords}

The spinal cord was exposed by removing the dorsal portion of the epaxial musculature and the neural arches of the vertebrae and then fixed in situ for 30-60 minutes, after which the portion of the cord in the region of the HRP application was cut into pieces, 7-9 $\mathrm{mm}$ long, which were further fixed by immersion for at least 2 hours in glutaral. dehyde and then placed overnight in a solution of $30 \%$ sucrose and $0.75 \% \mathrm{NaCl}$. The cords were embedded in a block of gelatin (10\% gelatin, $30 \%$ sucrose) that was trimmed, fixed overnight in phosphate-buffered $2 \%$ glutaraldehyde with $30 \%$ sucrose, frozen, and serially sectioned at $40 \mu \mathrm{m}$-usually in the transverse plane, occasionally in the horizontal. Sections were mounted on gelatin-subbed slides.

All sections were treated for peroxidase by using a modification of the cobalt intensification of the diaminobenzidine (DAB) reaction (Adams, '77). Alternate sections were counterstained in 10\% aqueous neutral red (Mesulam, '78) or in $0.5 \%$ methyl green. All sections were dehydrated in alcohols, cleared in xylenes, and mounted under a coverslip in Permount.

In spinal cords treated for peroxidase from sham-labeled or unlabeled animals there was reaction product associated only with blood cells (in mudpuppies) or with both blood cells and the endothelial lining of blood vessels (in goldfish); there was no reaction product associated with motoneurons. The reaction product in blood cells or vessels was readily distinguished from the reaction product in labeled motoneurons from HRP experiments. In only a few instances did endogenous peroxidase obscure portions of underlying labeled motoneurons in sections of cords from experimental animals.

\section{Processing of muscle}

In some cases, portions of the musculature from goldfish were treated for peroxidase to determine the extent of the HRP application. After the fish were perfused and the spinal cord was removed, the fish were frozen and the tail in the area of the labeling was cut by hand with a razor blade into serial transverse sections $0.5-3 \mathrm{~mm}$ thick. The sections were treated for peroxidase with $\mathrm{DAB}$. Tracings of the sections were drawn with the aid of a dissecting microscope and a camera lucida, and the extent of the red musculature and the HRP reaction product was indicated on the tracings.

\section{Cholinesterase staining}

Portions of the red and white musculature from goldfish were fixed in $4 \%$ formaldehyde, frozen, sectioned at $20-40$ $\mu \mathrm{m}$, and stained for cholinesterase by using a modification of the Naik-Koelle procedure (Naik, '63) to reveal the locations of motor endplates.

\section{Analysis}

Reconstruction of locations of motoneurons. The locations of motoneurons were reconstructed by using camera lucida tracings of serial sections of spinal cords onto transparent sheets of polyester on which the positions of labeled and unlabeled motoneurons were indicated. The positions of motoneurons from a series of sections were plotted onto a representative section from within the series to produce summary diagrams of their distribution. Tracings of sec- 
tions were aligned by using the central canal and the midline of the cord.

Cross-sectional areas of motoneurons and axons. The cross-sectional areas of labeled profiles were measured at a total magnification of 645-670 times by using a Zeiss MOP3 interfaced with an IBM Personal Computer. The areas of the cell body and primary dendritic processes (processes arising directly from the cell body) in the section were included in the measurements. This seemed the most objective estimate of size, because many of the profiles were comet-shaped (e.g., Fig. 8D), and in these, the extent of the "cell body" was not well defined. Usually a nucleus was visible in those labeled profiles whose areas were included in size histograms. However, some of the measured profiles contained solid black reaction product, which likely obscured the nucleus.

The cross-sectional areas of myelinated axons in nerves were measured by tracing along the internal edge of the myelin sheaths on camera lucida tracings of nerves enlarged 1,595-1,640 times. Calibrations were established by using a stage micrometer. The number of myelinated axons in each nerve was also counted on these camera lucida tracings.

Statistics. Statistical comparisons of frequency histograms of the cross-sectional area of motoneurons were performed by using a two-tailed nonparametric KolmogorovSmirnov two-sample test (K-S test) (Sokal and Rholf, '81). The assumptions of the K-S test are independence of observations and continuous variables. Both of these assumptions were met in the experiments reported here. A nonparametric test was chosen because the skewed size distributions of motoneurons violated the assumption of normality underlying most parametric tests. Distributions compared in this paper are considered significantly different when $P<.05$.

\section{RESULTS \\ General remarks}

In the following results, I deal first with observations from goldfish and then with those from mudpuppies. For both, I first consider the organization of the axial musculature and the spinal nerves innervating it. Then I describe the general features of HRP-filled motoneurons in the medial motor column. Finally, I deal with experiments designed to determine how the organization of motoneurons in the motor column relates to the organization of the musculature they innervate.

\section{Goldfish}

Axial musculature. The axial musculature was examined in gross dissections and in transverse and sagittal sections. It consists of a rostrocaudal series of repeated units (myomeres) separated by connective tissue septa (myosepta). These myomeres are visible in gross dissection but are especially obvious in sagittal sections through the mus. culature, as shown in Figure 1A,B. In favorable sections, individual muscle fibers were observed running from myoseptum to myoseptum. The myomeres are complexly folded; any cross section through one side of a fish cuts through several overlapping myomeres.

Red and white regions within the myomeres are evident in transverse sections through the tail (Fig. 2). The red muscle forms a relatively narrow band just beneath the skin. The much larger mass of white muscle lies deep to the red. The musculature on each side of the tail is divided into dorsal (epaxial) and ventral (hypaxial) portions by a horizontal septum (Fig. 2). The band of red muscle is thickest near the horizontal septum, and is thinner dorsally and ventrally.

Spinal nerves: Rami. The branching pattern of postanal spinal nerves from the rostral end of the tail is illustrated
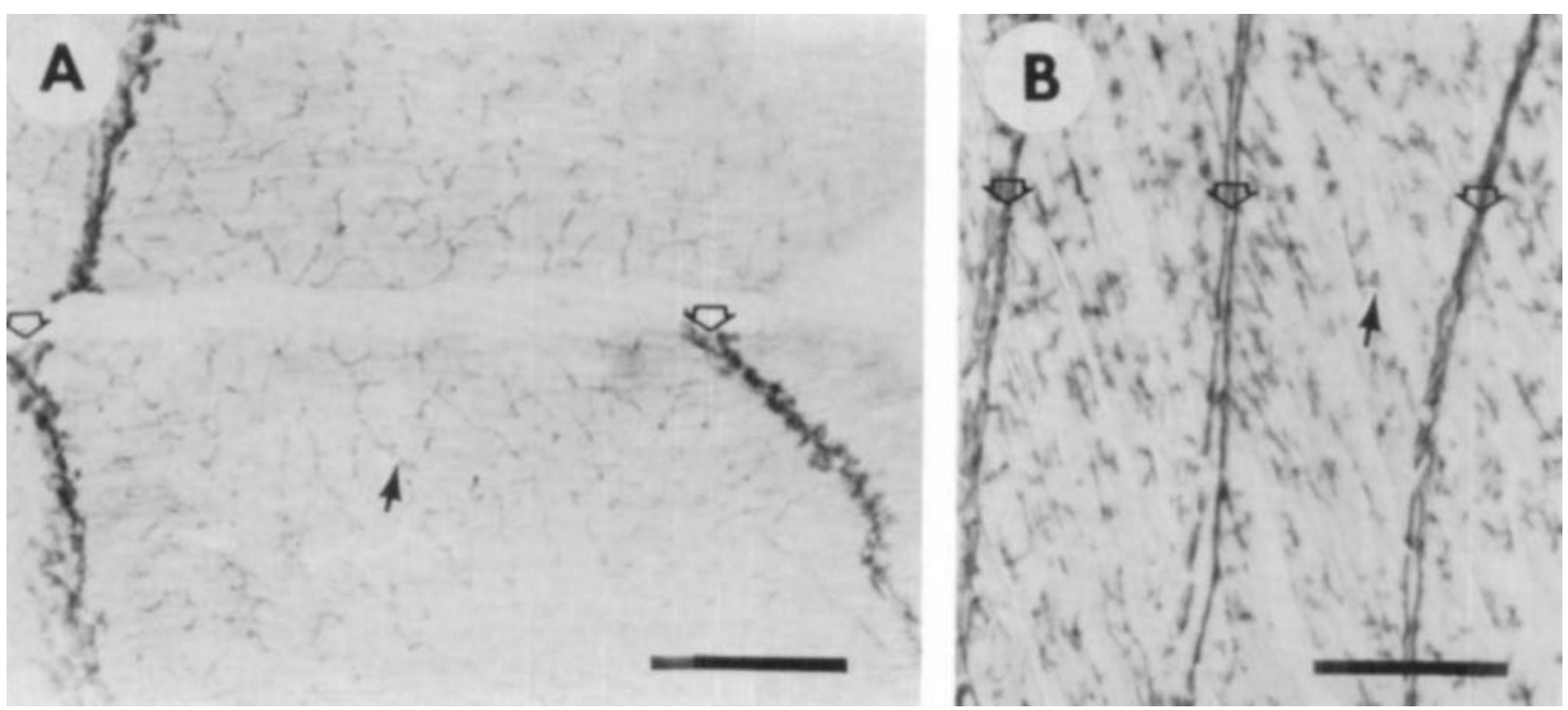

Fig. 1. Cholinesterase staining of axial musculature in goldfish. Sagittal frozen sections through the red (A) and white (B) axial muscle stained for cholinesterase. The myotendinous junctions at the myosepta (open arrows) stain heavily. Stained neuromuscular junctions (solid arrows) are distrib- uted along muscle fibers from myoseptum to myoseptum in both the red and white muscle. The distances between myosepta in A and B are different because the distance varies with depth in the musculature. Bars $=500 \mu \mathrm{m}$ 


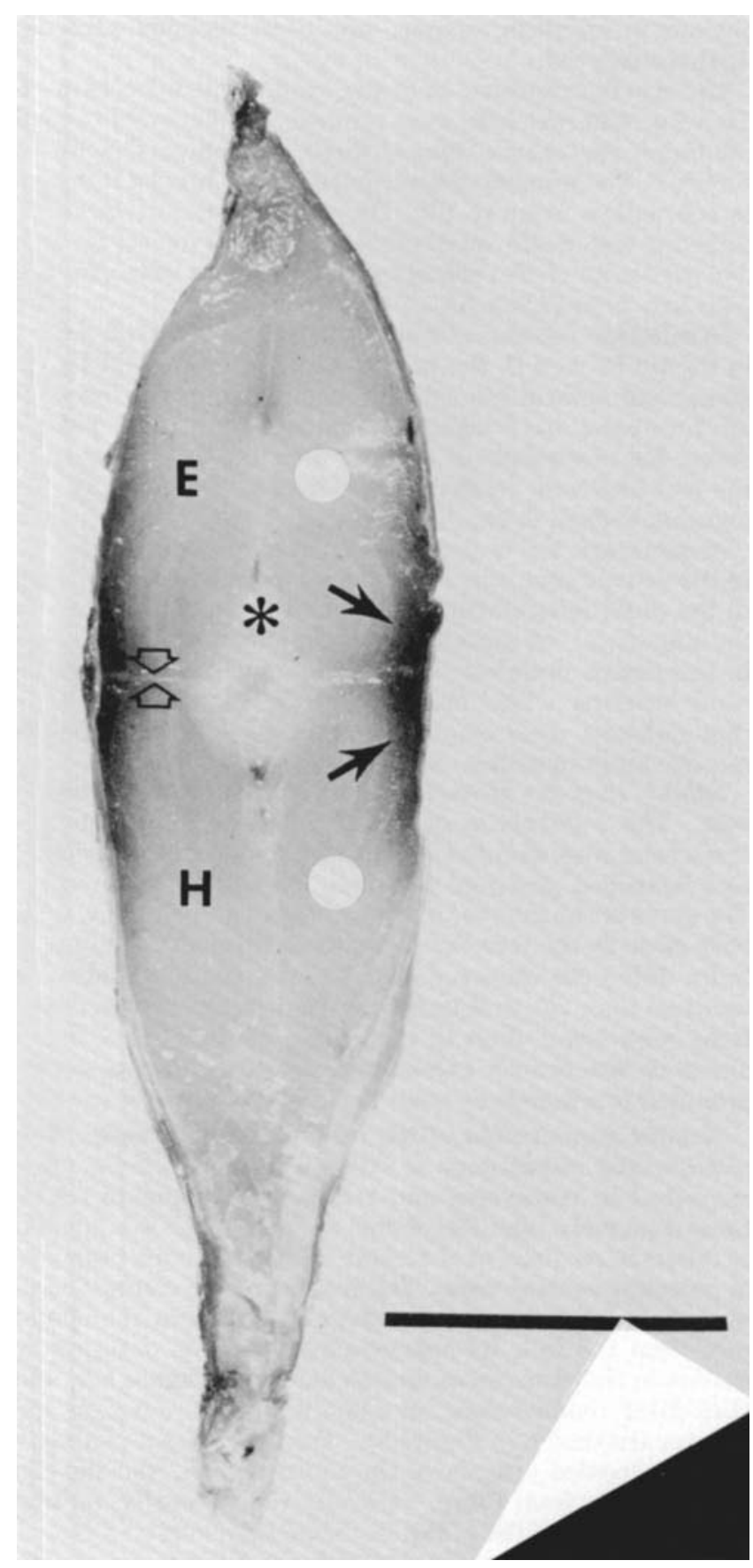

Fig. 2. A cross section through the tail of a 152-mm (standard length) goldfish, showing the division of the musculature into a superficial red (solid arrows) and deeper white (the white dots are within the white muscle) portion. The muscle is also divided into dorsal (epaxial, $\mathbf{E}$ ) and ventra (hypaxial, H) portions by a horizontal septum (open arrows). An asterisk marks the location of the spinal cord. The section was cut from a freshly killed, frozen goldfish. Bar $=10 \mathrm{~mm}$.

by a diagrammatic cross section of the tail in Figure 3 and by a drawing showing the region near the spinal cord in Figure 4. A dorsal (d) and a ventral (v) root arise from the dorsal and ventral portions of the cord. Each root has three major rami: dorsal, medial, and ventral.

The dorsal ramus from the dorsal root (DRd, Fig. 3) runs along the neural spine rostral to the site at which its parent

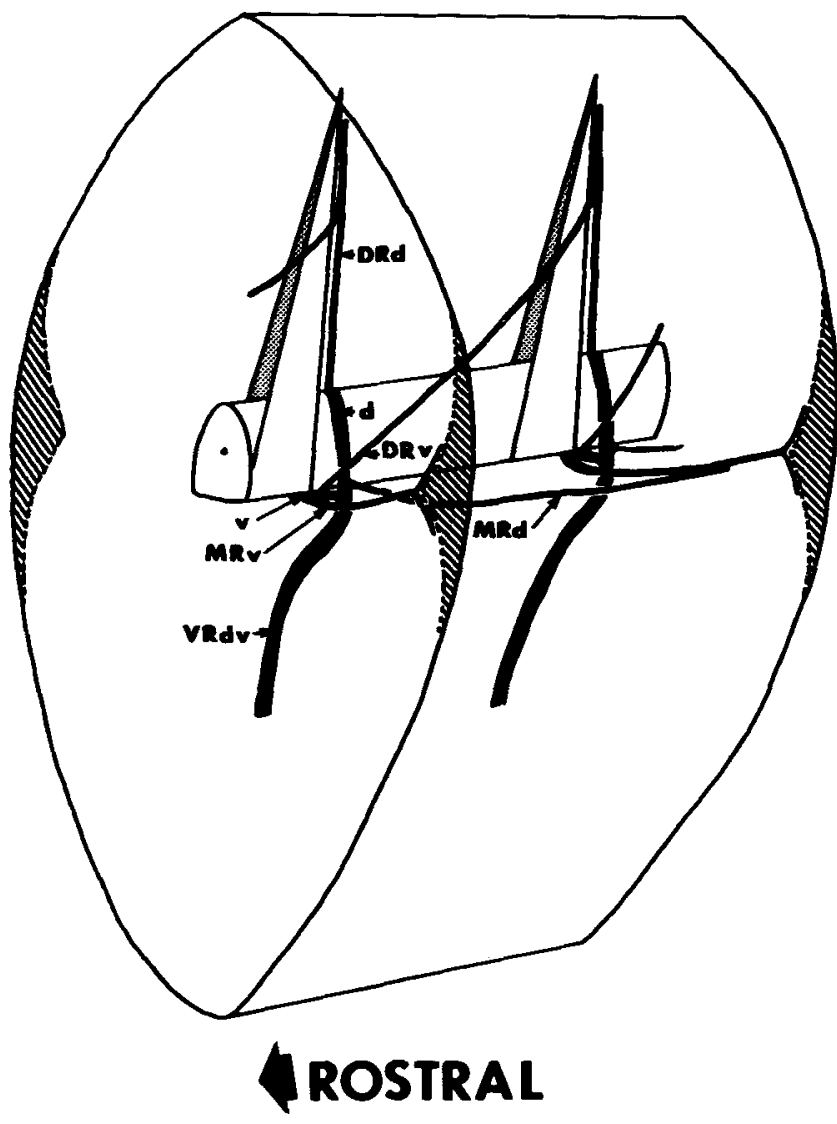

Fig. 3. Diagrammatic view of the branching pattern of spinal nerves from the tail of a goldfish. The spinal cord and the neural spines of the vertebrae of two segments are shown within a cross section of the tail musculature. Rostral is to the left. The red muscle on either side of the body is shaded with black lines. The spinal nerves are shown in solid black. $v$, ventral root; DRv, dorsal ramus of ventral root; $M R v$, medial ramus of ventral root; VRdv, ventral ramus formed by the union of a branch of the dorsal and ventral roots; d, dorsal root; DRd, dorsal ramus of the dorsal root; MRd, medial ramus of the dorsal root.

dorsal root exits from the vertebral column. The dorsal ramus of the ventral root (DRv, Fig. 3) runs caudally and dorsally and comes to lie along the neural spine caudal to the site at which the ventral root exits from the vertebral column, where it joins the dorsal ramus from the dorsal root of the next caudal body segment. The dorsal rami from the ventral root send small branches into epaxial muscle and also enter the dorsal fin.

The medial rami run in the horizontal septum to the lateral portion of the tail. The one from the dorsal root arises proximal to the junction of dorsal and ventral roots (MRd, Figs. 3, 4) and runs caudally and laterally in the septum. The one from the ventral root in some cases arises proximal to the junction (MRV, see the caudal segment in Fig. 4) or in other cases arises from the combined ventral and dorsal roots as they run ventrally along the vertebral body (MRdv, see the rostral segment in Fig. 4). The medial ramus from the ventral root runs laterally in the septum to the red muscle where it splits into two branches that run deep to the red muscle in the epaxial and hypaxial portions of the myomere (Fig. 3).

After giving rise to the medial rami, the remaining branches of the dorsal and ventral root join, forming the 


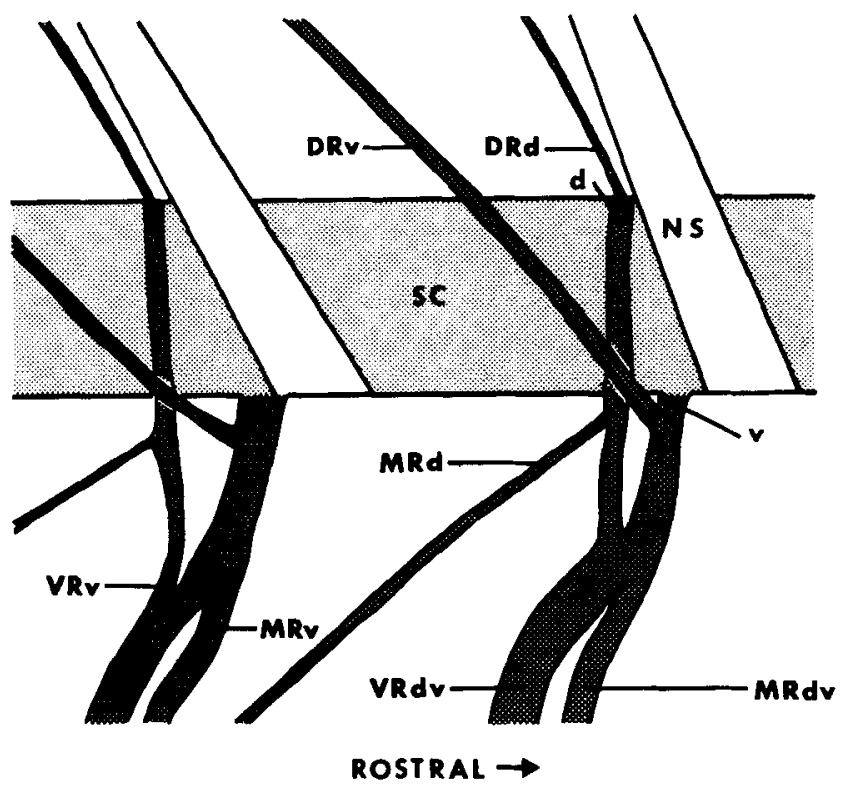

Fig. 4. Drawing based on a camera lucida tracing of a lateral view of spinal nerves from the tail of a goldfish, showing the nerves near the spinal cord. Rostral is to the right. Two adjacent spinal nerves with slightly different branching patterns are shown. In the segment on the right, the ventral root (v) exits from the spinal cord (SC) and forms two branches. One of them, the dorsal ramus (DRv), runs dorsally and caudally. The other joins a branch of the dorsal root, and then the combined nerve splits into a medial ramus (MRdv) and a ventral ramus (VRdv). In the left segment, the ventral root forms three branches, a dorsal ramus, a ventral ramus (VRv), and a medial ramus (MRv), before any of them join branches of the dorsal root. NS, neural spine. Bar $=1 \mathrm{~mm}$.

ventral ramus (VRdv, Fig. 3), which runs ventrally, deep in the hypaxial muscle. The ventral rami send branches into the the hypaxial muscle and can also be traced into the anal fin.

The most important feature of the nerve branching pattern in the context of this study is that there are three major rami arising from the ventral root, and these presumably contain the axons of motoneurons. Two of these, the dorsal and ventral rami (DRv, VRv), run deep in the epaxial and hypaxial muscle, respectively. The third, the medial ramus (MRv), runs laterally, without branching, to the red muscle, where it then branches into both the epaxial and hypaxial muscle. These observations suggest that a separate ramus of the ventral root, the medial ramus, supplies the motor innervation of the superficial red muscle. The other two rami apparently innervate deeper musculature.

Spinal nerves: Axons in the ventral root and its rami. In this section I deal only with the ventral root and branches of the ventral root that did not receive any contribution from the dorsal root. Branches of the ventral root are composed almost exclusively of myelinated axons of various diameters. In contrast (compare Fig. 5A to B), branches of the dorsal root consist predominantly of small myelinated axons as well as large areas that lack myelin, stain heavily with safranin-O, and which were shown electron microscopically to contain large numbers of nonmyelinated axons. Because of these differences, in those nerves in which branches of the dorsal root joined with branches from the ventral root, the contribution from the dorsal root was obvious in semithin sections, and these sections were not further analyzed.

The size distributions of axons in the ventral roots $(n=6$ from five different fish) were unimodal and skewed toward the larger size classes. One of these, labeled $v$, is shown in Figure 6 . The number of myelinated axons ranged from 117 to 164 with a mean of 135 . The ventral roots always contained a few (8-12) relatively very large axons (Fig. 5A), and in five out of six ventral roots these axons were grouped together, as in Figure 5A.

In semithin sections of rami from the ventral root, shown in Figure $5 \mathrm{C}$ and $\mathrm{D}$, the largest axons were present in the dorsal and ventral but not the medial ramus $(n=5$ sets of all three rami and 8 additional pairs of ventral and medial rami). Measurements of the size distributions of axons in the root and rami confirmed this impression (compare histograms in Figs. 6, 7).

In summary, the largest axons, usually grouped together in the ventral root, run in the dorsal and ventral rami deep in the axial musculature, but not in the medial ramus to the superficial red muscle. The absence of these large axons in the ramus entering red muscle, and their presence in rami entering white muscle, provide tentative evidence that different sizes of axons innervate different types of muscle: large to white, small to red.

Spinal nerves: Branching of axons in the ventral root. The numbers of axons in the ventral root and its three rami were counted to determine whether axons in the root branched proximal to where they entered the rami. The sums of the number of axons in the rami (Table 1) were very close to the number of axons in the roots. The maximum difference observed was $7 \%$; the average difference was less than $2 \%$, and in two of the five, the counts in the rami were lower than in the root. I conclude that motor axons do not branch extensively, and perhaps not at all, proximal to where they enter the major peripheral rami.

General organization of the medial motor column. The location and morphology of HRP-filled motoneurons were examined in transverse and horizontal sections of spinal cords from more than 70 goldfish in which HRP was applied to different portions of the axial musculature, or branches of postanal ventral roots. The medial motor column occupied the ventral portion of the gray matter in the spinal cord from the tail. Its approximate extent is outlined by dashes in the transverse section shown in Figure 8A, and HRP-filled motoneurons spread throughout much of the column are shown in Figure 8C. The most dorsal motoneu rons are located just above the central canal, and the column extends from these, ventrally and laterally, around the lateral side of the Mauthner axon (M-axon).

The size distributions of motoneurons, like the size distributions of axons in the ventral roots, were unimodal and skewed toward the larger size classes. There was a large range of sizes of motoneurons (see Figs. 13 and 15 from the results of muscle labeling experiments); the areas of the largest were 8-14 times the smallest. The largest ones were generally the most dorsal (Figs. 8C,D, 9A,B); the smaller ones were the most ventral (Fig. $8 \mathrm{C}, \mathrm{D}$ ).

Dendritic morphology of motoneurons in the medial motor column. In semithin sections stained with toluidine blue there was a lightly stained region slightly dorsal and lateral to the area occupied by the motoneurons (Fig. 8A) Dendritic processes of motoneurons, indicated by arrows in Figure $10 \mathrm{~B}$ and $\mathrm{C}$, ramified extensively in this region. Most. large, primary dendrites projected laterally or dorsolat- 

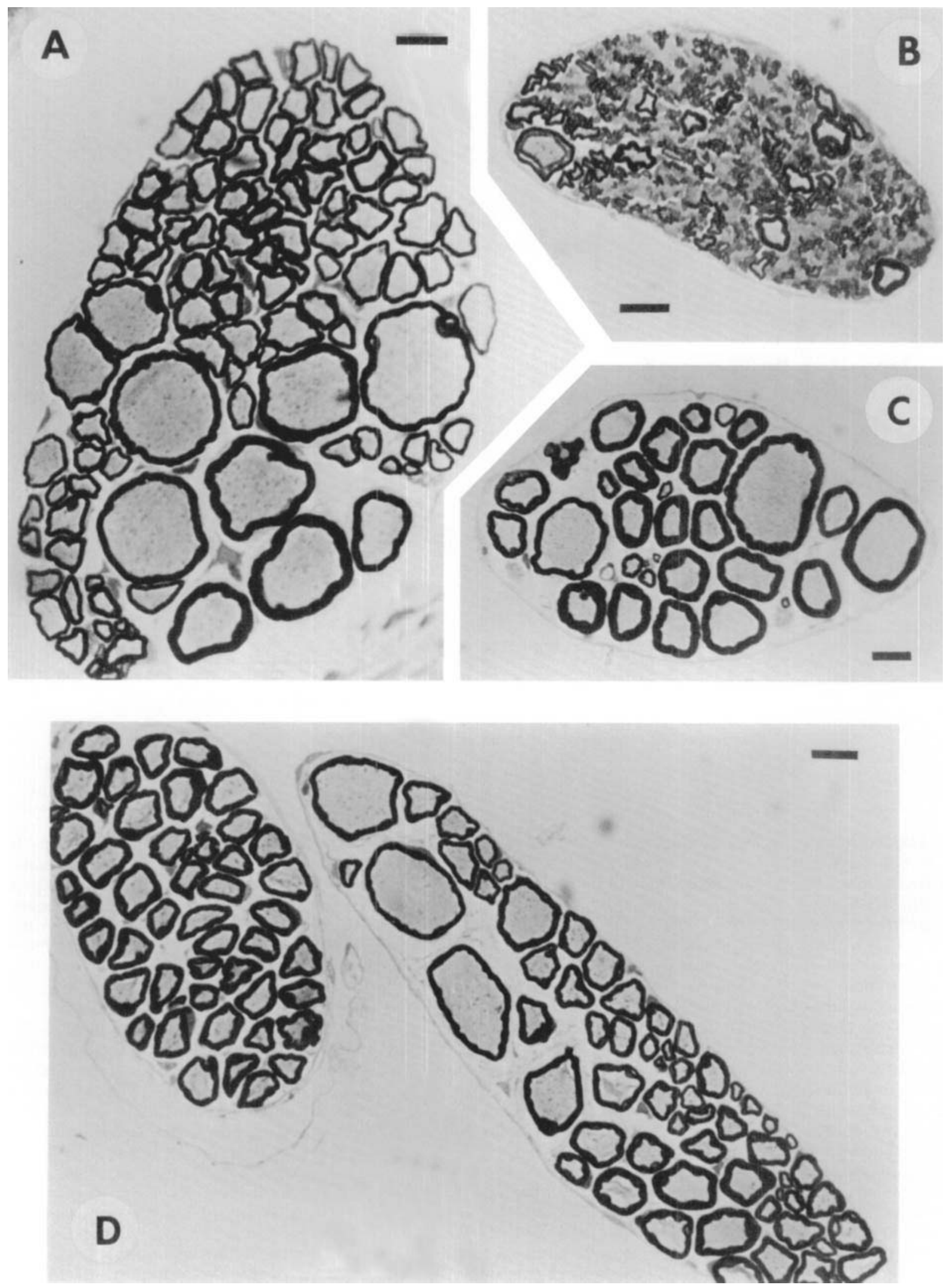

Fig. 5. Axons in branches of spinal nerves of goldfish. Transverse semi- on the left, a medial (MRv), and on the right, a ventral (VRv) ramus from a thin sections stained for myelin: (A) a ventral root (v), (B) a dorsal ramus of the dorsal root (DRd), (C) a dorsal ramus from a ventral root (DRv), and (D)

ventral root. Only the medial and ventral rami are from the same body segment. Bars $=10 \mathrm{~km}$. 

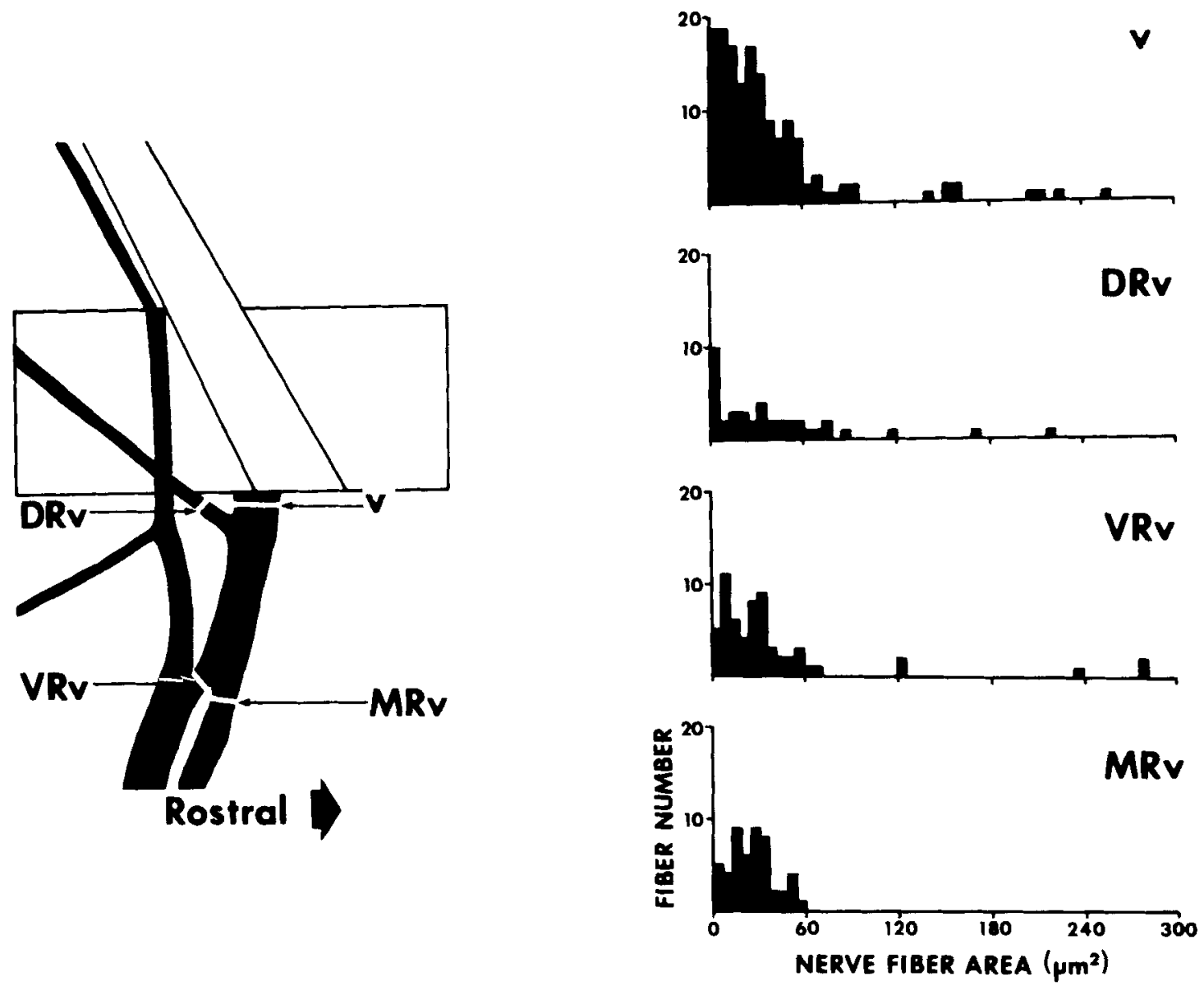

Fig. 6. Size histograms of the cross-sectional areas of axons in the ventral root ( $v$ ), and the three branches of the root (DRv, VRv, MRv) from a single spinal nerve from the tail of a goldfish. The locations of the cross sections used to generate the histograms are shown in the diagram of the nerve branches on the left.

erally, then bifurcated, sending processes rostrally and caudally in the cord (Fig. 9B). In horizontal sections, these dendrites formed a longitudinal band lateral to the central canal (Fig. 10C).

The pathways of motor axons. The motor axons can be divided into two major groups, shown in Figure 11A and B, based upon whether they pass medial or lateral to the Maxon along their course to the ventral root. The largest axons arose from the large dorsal motoneurons and always ran medial to the $\mathrm{M}$-axon as they approached the root (11A,B). These axons often made sharp turns, sometimes nearly a right angle, toward the medial side of the M-axon (Fig. 10A). In addition to the large axons, smaller ones (Fig. $11 \mathrm{~A}, \mathrm{~B})$, originating from smaller motoneurons, also ran medial to the M-axon. The large and small axons formed two discrete groups, with the larger axons occupying a more dorsal position than the smaller ones.

Although some smaller axons ran medial to the M-axon as they approached the root, most of the small ones coursed lateral to it (Fig. 11A,B) and usually arrived at the ventral edge of the cord rostral to the medial axons destined to exit in the same ventral root. As these two groups were traced caudally to the ventral root in serial sections, the medial group coursed ventrolaterally, and the small axons from the medial group joined with, and became indistinguisha- ble from, the small axons in the lateral group (Fig. 11C,D). At the ventral edge of the cord the largest axons, still segregated from the small ones, lay medial in the group of axons destined to exit in the root. A similar segregation of large and small axons at the ventral edge of the cord was visible in semithin sections stained with toluidine blue (Fig. 8B). As indicated earlier (see Figs. 5, 6), the largest axons usually remained grouped together in the root and entered the dorsal and ventral but not the medial ramus.

The central pathways of axons in the three peripheral rami were examined by selectively labeling the individual rami with HRP. Because counts of axons, discussed previously, indicated that most individual axons in the ventral root did not branch and enter more than one of the three rami, HRP selectively applied to one ramus should result in few, if any, labeled axons in other rami. Therefore, to control for any leakage of HRP, all three rami were removed, sectioned, and treated for HRP to confirm that labeled axons were present only in the ramus exposed to HRP; only experiments in which rami were selectively labeled are included in the following results.

HRP selectively applied to the medial ramus (MRv, $n=6$ ) filled only small axons in the group running lateral to the M-axon (Fig. 11E,F). Similar labeling of the ventral ramus, dorsal ramus, or combined medial and ventral rami $(n=9)$ 

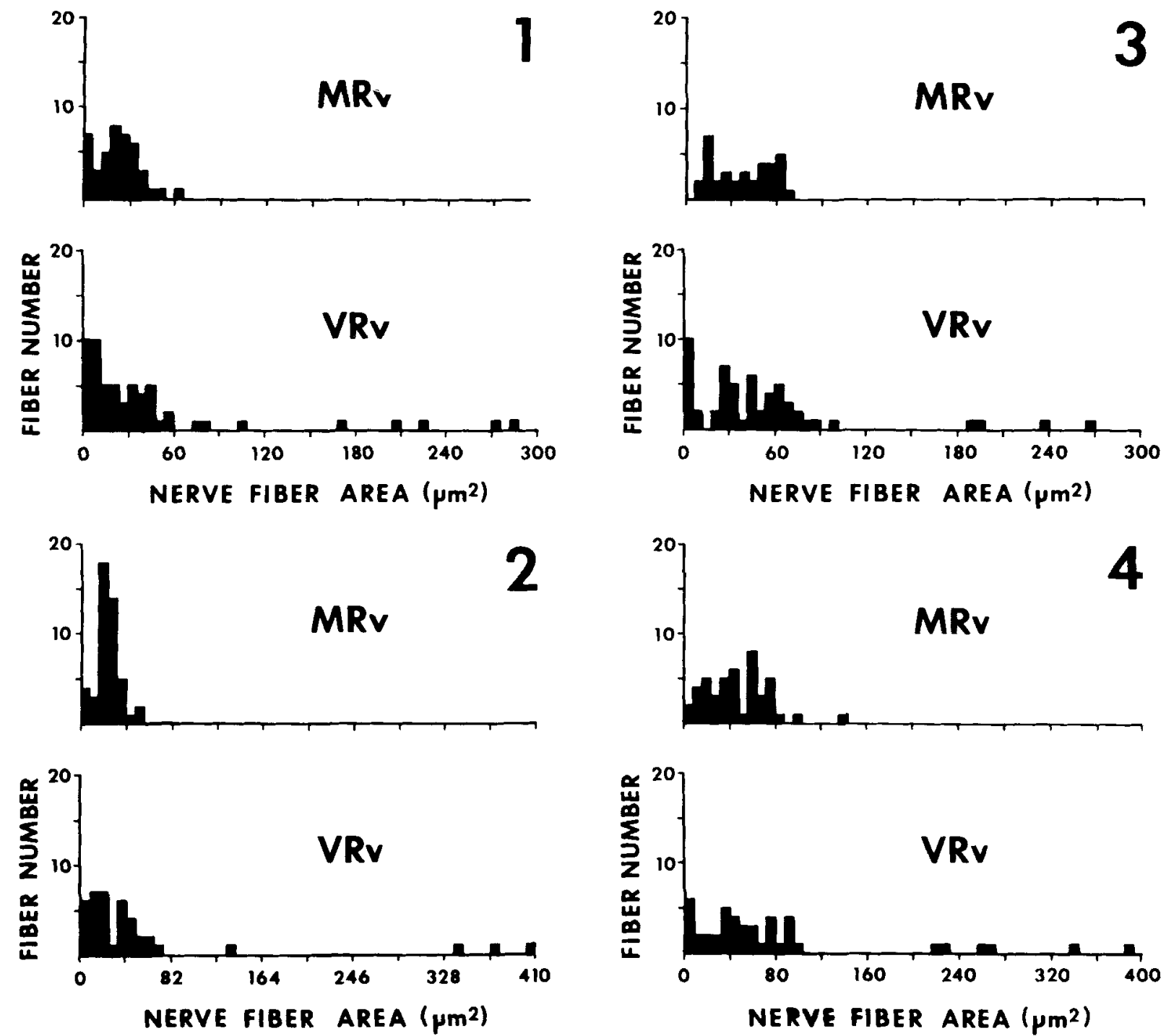

Fig. 7. Histograms of the cross-sectional areas of axons in the medial (MRv) and ventral (VRv) rami of single ventral roots from four different fish (1-4).

TABLE 1. Summary of the Number of Axons in Spinal Nerve Branches of Goldfish

\begin{tabular}{lccccc} 
& & \multicolumn{3}{c}{ Rami } & Total of \\
\cline { 3 - 5 } Case No. & Ventral root & Dorsal & Ventral & Medial & \begin{tabular}{c} 
rami \\
\hline c93
\end{tabular} \\
c77 & 121 & 22 & 60 & 42 & 124 \\
c68 & 126 & 31 & 44 & 45 & 120 \\
c91-7 & 151 & 40 & 60 & 50 & 150 \\
c91-9 & 117 & 28 & 38 & 48 & $122^{1}$ \\
\hline
\end{tabular}

${ }^{1}$ In case number 917 eight axons were found outside of the major rami, adjacent to the medial and ventral rami.

always filled axons both medial and lateral to the M-axon, including some of the largest axons in the medial group.

In summary, the motor axons are to some extent segregated along different pathways in the cord that are related to their paths in the periphery. Large axons, from large motoneurons, always pass medial to the M-axon and only enter the dorsal and ventral rami in the deep white muscle.
Small axons, from small motoneurons, pass either medial or lateral to the M-axon and enter all three rami. The medial ramus to the red muscle contains only small axons that originate from small motoneurons, and all run lateral to the M-axon in the cord. These observations extend the earlier tentative conclusion that different populations of axons innervate red and white muscle; they suggest that 

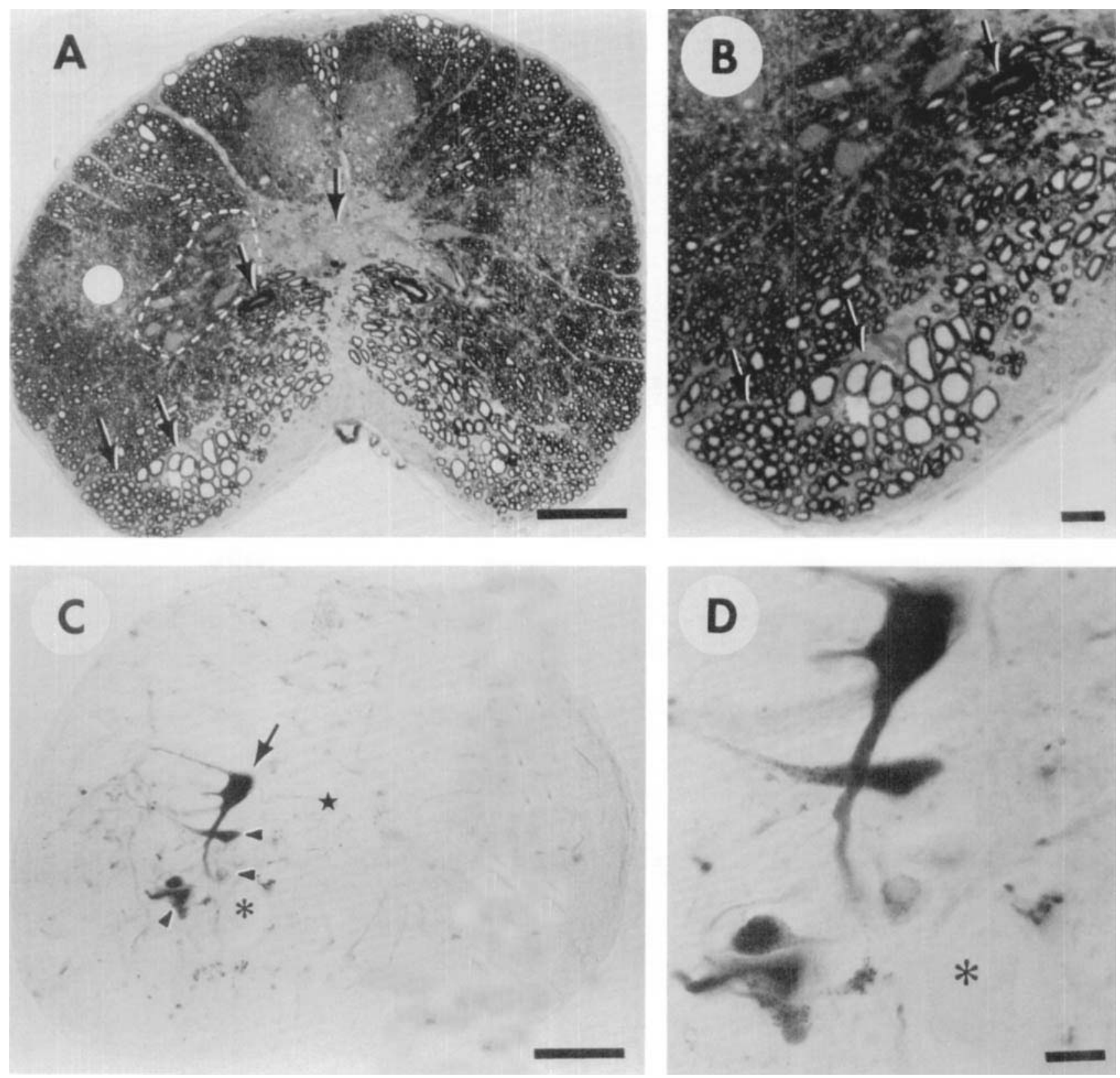

Fig. 8. The gross morphology of the spinal cord of goldfish, and the general location of the motoneurons, their dendrites, and their axons. A. A $1-\mu \mathrm{m}$ semithin transverse section of the cord from the tail stained with toluidine blue. The arrows indicate, from top to bottom, the central canal, the Mauthner axon on one side, and the motor axons located ventrally just before they exit in the ventral root. White dashes roughly outline the region occupied by motoneurons. A white dot shows the lightly stained region occupied by the dendrites of motoneurons. Bar $=100 \mu \mathrm{m}$. B. A more highly magnified view of the bottom left portion of figure (A) showing the Mauthner axon (top arrow) and the motor axons (bottom arrows). The largest

axons are located on the medial side of the group of motor axons. Bar $=20$ $\mu \mathrm{m}$. C. A transverse section (not counterstained) of the spinal cord showing, on the left side, HRP-filled motoneurons spread throughout most of the transverse extent of the medial motor column. A star shows the position of the central canal, and an asterisk the location of the Mauthner axon on the left side. An arrow points to a very large motoneuron in the dorsal portion of the column. Arrowheads point to smaller motoneurons, ventral to the large one. Bar $=100 \mu \mathrm{m}$. D. A more highly magnified view of the HRP-filled motoneurons in C. An asterisk marks the Mauthner axon. $\mathrm{Bar}=20 \mu \mathrm{m}$.

large motoneurons innervate white muscle and that only small ones innervate red. The differences in the motoneurons innervating red and white muscle are examined further as part of the next series of experiments.

HRP labeling of axial musculature. These HRP-labeling experiments fall into two major classes: (1) those designed to examine differences between motoneurons innervating the dorsal (epaxial) and the ventral (hypaxial)

portions of the myomeres and (2) those designed to examine differences between motoneurons innervating the superficial red and the deep white portions of the myomeres. All of the spinal cords for this series of experiments were cut into serial transverse sections.

Motoneurons innervating epaxial or hypaxial musculature. In six fish, the motoneurons innervating the dorsal and ventral extremes of the myomeres were compared by 

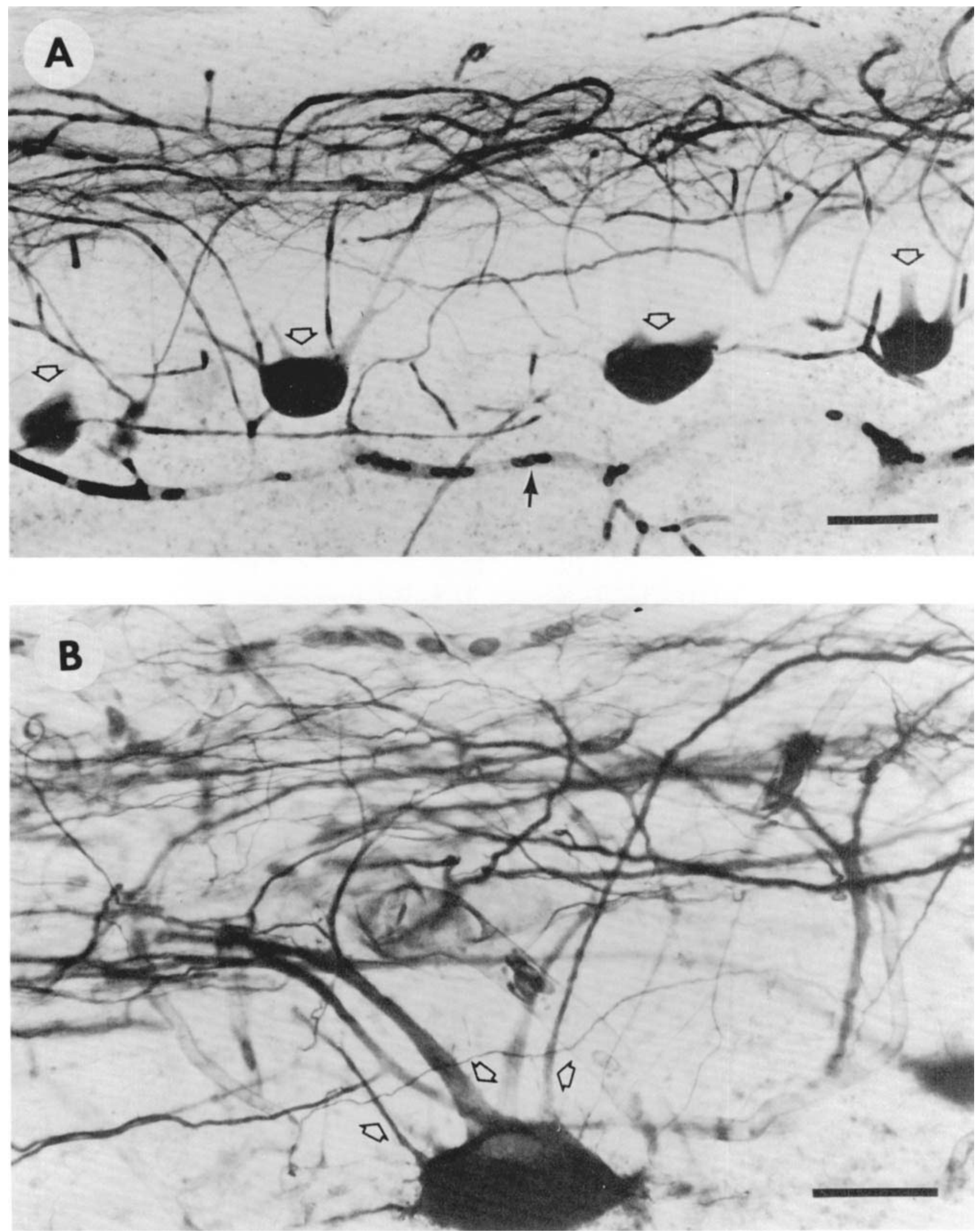

Fig. 9. Morphology of large motoneurons in goldfish. Horizontal sections of the spinal cord showing large HRP-filled motoneurons. In both A and B rostral is to the left, and the lateral edge of the cord is toward the top. A. A section near the level of the central canal, showing a row of four regularly
spaced HRP-filled cell bodies (open arrows) of large dorsal motoneurons. A

solid arrow marks a blood vessel. Bar $=100 \mu \mathrm{m}$. B. A portion of the dendritic arbor of a large motoneuron (not one of those shown in A). Dendrites (open arrows) arise from the cell body located at the bottom of the photo and run

laterally (toward the top of the figure) and then rostrally or caudally within the band of dendrites from other motoneurons. $B a r=50 \mu \mathrm{m}$. 

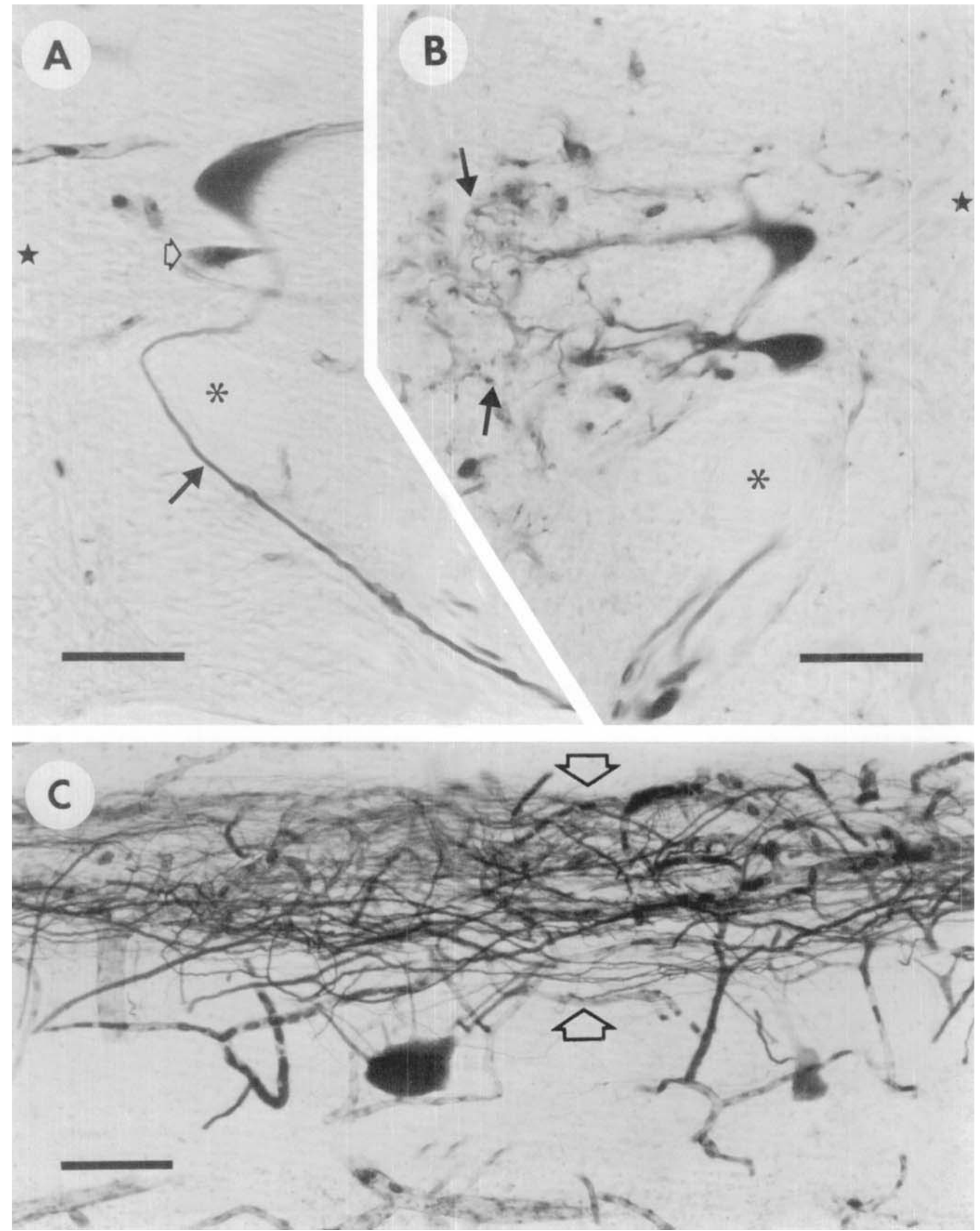
labeling, with HRP, the dorsal portion of the epaxial musculature on one side and the ventral portion of the hypaxial musculature on the opposite side of the same fish. HRP. soaked pledgets were inserted into the musculature on either side of the fish by passing them through the superficial portions of the myomeres into the deeper muscle. No attempt was made to confine the labeling to an individual myomere because the folding of the myomeres and the potential for leakage to adjacent myomeres made the labeling of a single myomere difficult. Rather, the goal was to label motoneurons projecting to the extreme dorsal (superficial and deep) and ventral (superficial and deep) portions of the myomeres.

The motoneurons innervating epaxial and hypaxial musculature did not occupy different regions in the medial motor column. Figure 12 shows reconstructions of the locations of labeled motoneurons in two representative experiments. HRP applied to either epaxial or hypaxial muscle filled motoneurons throughout much of the mediolateral and dorsoventral extent of the motor column. There was some concentration of the labeled motoneurons in the dorsal portion of the motor column on both sides of the cord, but motoneurons in its ventral portion were also labeled. HRP-filled motoneurons on both sides were spread over several spinal segments; this was expected because muscle in more than one myomere was exposed to HRP.

There were no consistent differences in the size distributions of motoneurons innervating epaxial and hypaxial muscle. The distributions from all six experiments are shown in Figure 13. In every pair both distributions were skewed toward the larger cell sizes. The very large motoneurons in the dorsal portion of the column, as well as smaller, more ventral ones, were labeled in each case.

It is unlikely that the similarities in the populations of motoneurons filled on the two sides of the cord were a consequence of leakage of HRP from the labeling site in epaxial muscle to the labeling site in hypaxial muscle or vice versa, because in sections of the tail musculature treated for peroxidase, the reaction product was confined to a relatively narrow region (less than $2 \mathrm{~mm}$ wide) along the path of entry into the muscle, while the distance between the two labeling sites was $10 \mathrm{~mm}$ or more. The similarities were also probably not the result of individual motoneurons innervating both epaxial and hypaxial muscle, because counts of axons (see earlier Results) indicated little or no branching proximal to where axons in the ventral root entered the major rami into epaxial or hypaxial muscle.

In more than 25 additional experiments in which HRP was applied to both superficial and deep muscle at various places throughout the dorsoventral extent of the myo-

Fig. 10. Morphological features of HRP-filled motoneurons from goldfish. A. The right side of a transverse section of the spinal cord showing the axon (solid arrow) of a large HRP-filled motoneuron looping around the medial side of the Mauthner axon (asterisk). A star marks the central canal. A smaller HRP-filled motoneuron (open arrow) lies below the large one. Bar= $50 \mu \mathrm{m}$. B. The left side of a transverse section of a spinal cord showing the lateral dendritic arbors (arrows) of some HRP-filled motoneurons. A star is located in the central canal, and an asterisk marks the Mauthner axon. $\mathrm{Bar}=50 \mu \mathrm{m}$. C. Horizontal section of a spinal cord through the region occupied by dendrites in B. Rostral is to the left. The lateral edge of the spinal cord is toward the top. The dendrites of motoneurons form the band of labeled processes (open arrows) at the top of the figure. Bar $=100 \mu \mathrm{m}$. meres, labeled motoneurons were always found through. out the transverse extent of the motor column. No matter where the labeling was performed in the myomeres, as long as both superficial and deep muscle were labeled, both large and small motoneurons were filled.

Additional support for the conclusion that similar populations of motoneurons innervate epaxial and hypaxial muscle was obtained by selective labeling of peripheral nerves. The dorsal and ventral rami of spinal nerves enter the deep epaxial and hypaxial muscle, respectively. Both the dorsal and ventral rami contain large and small axons (Figs. 5, 6), and HRP applied to them fills both large and small motoneurons in the cord. Motoneurons filled from both rami were located rostral to the ventral root of the labeled segment and were spread longitudinally over one spinal segment from the root of the labeled segment to the next rostral one. When a dorsal ramus and a ventral ramus of the same segment on opposite sides of the tail were exposed to HRP, the rostrocaudal distributions of HRP. filled motoneurons on the two sides of the cord overlapped completely. Thus, the motoneurons filled from the dorsal or ventral ramus were not separated along the rostrocaudal axis of the spinal cord.

In summary, the motoneurons innervating the dorsal and ventral extremes of the myomeres occupy similar positions within the transverse extent of the medial motor column. Additionally, the rostrocaudal distributions of motoneurons with axons in the dorsal or ventral rami overlap extensively, suggesting that the motoneurons innervating epaxial and hypaxial muscle are also not segregated longitudinally. I conclude that the position of a motoneuron in the medial motor column is not related in a systematic way to the dorsoventral position of the muscle that it innervates within the myomeres.

Motoneurons innervating superficial red or deep white musculature. The motoneurons innervating red and white muscle could be most directly compared if HRP was applied to only white muscle on one side of a fish, and only red muscle on the opposite side of the same fish. However, this is difficult because when HRP is passed through red muscle into white muscle, both red and white muscle are exposed to HRP. Therefore, the data presented here involve experiments in which red or white muscle was labeled on one side of a fish and both red and white musculature was labeled on the opposite side of the same fish. The differences in the populations of motoneurons innervating red and white regions are inferred from these experiments by comparing the motoneurons innervating red plus white muscle on one side to those innervating only red, or only white, on the opposite side.

The red muscle was labeled in 21 fish by implanting HRP-soaked pledgets beneath the skin just above or below the lateral line, where the red muscle is thickest. This approach was used to minimize the likelihood of spread of the HRP through the relatively thin red muscle layer into deeper white muscle. On the opposite side of the same fish, both red and white musculature was labeled by inserting HRP-soaked pledgets through the superficial red muscle into the deeper white muscle near the lateral line. Motoneurons were successfully labeled on both sides of the cord in nine fish; in the others, very few or no cells were filled on the red-muscle side, and these are not considered below.

Figure 14 shows reconstructions of the locations of HRP. filled motoneurons from two representative experiments. HRP applied to only superficial red muscle filled motoneu- 

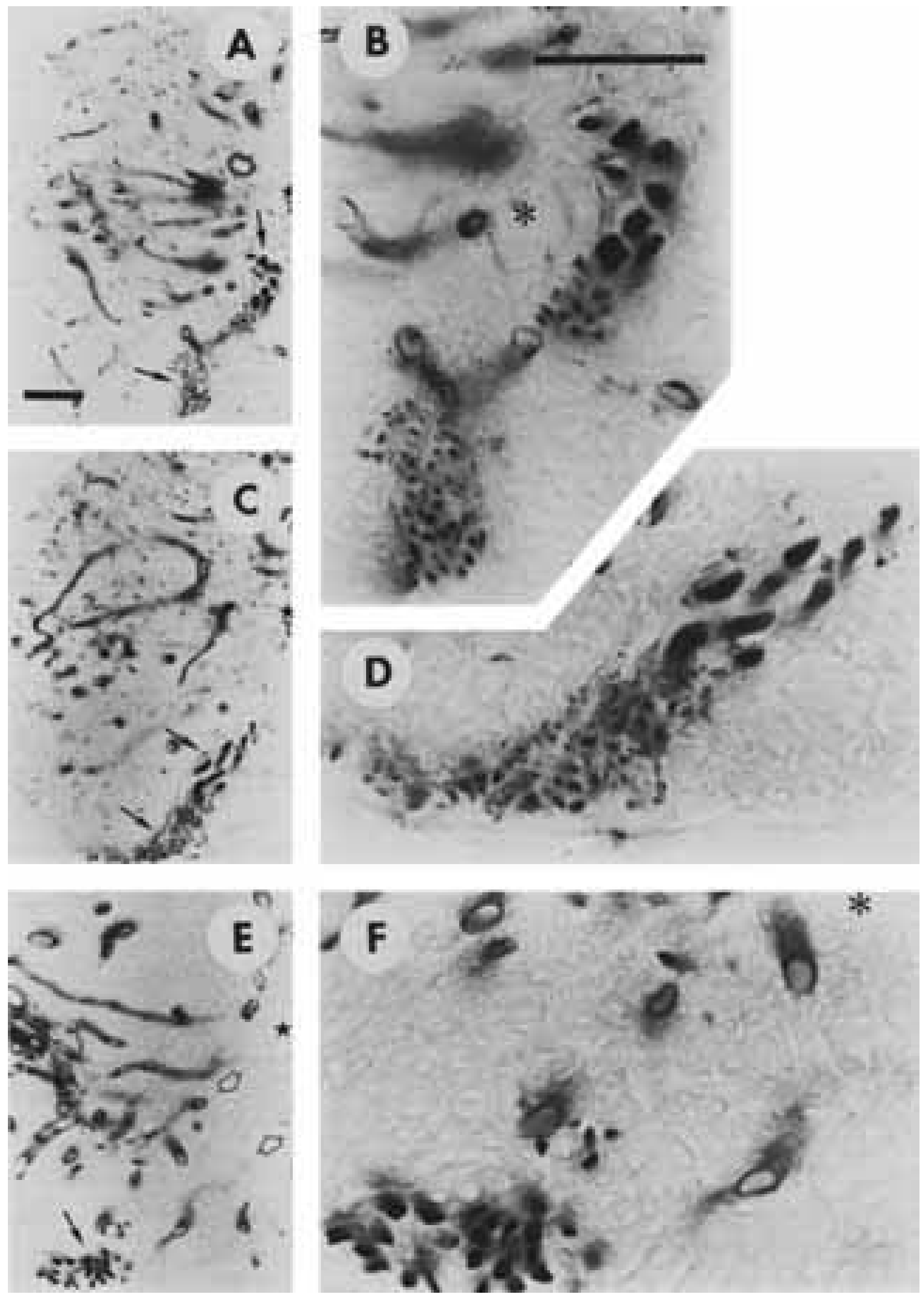

Figure 11 
rons confined to or strongly concentrated in the ventral portion of the motor column. The largest motoneurons, in the dorsal portion of the column, were generally not labeled. However, a few large dorsal motoneurons were lightly labeled in two animals. In contrast, HRP applied to both red and white muscle invariably filled motoneurons throughout the mediolateral and dorsoventral extent of the motor column (Fig. 14), always including the largest ones.

The size distributions from six of these experiments, showing the range of variability, are illustrated in Figure 15. The distributions from the red-plus-white-muscle side were skewed, with a relatively large population of small motoneurons and a "tail" of larger motoneurons. In contrast, usually only small motoneurons were filled on the side where only red muscle was labeled; the tail in the distribution from the red-plus-white-muscle side was absent. Often these size distributions were significantly different according to the statistical criteria given in Methods, but in some cases they were not. However, a size comparison alone is somewhat misleading because the larger cells, usually absent when only superficial red muscle was labeled, were not just very large-they also occupied a distinctive position in the dorsal portion of the motor column. Both their size and their position must be considered in any comparison.

The differences between the HRP-filled motoneurons on the two sides of the cord in the previous experiment may be related to the differences in the types of muscle (red vs. white) or the locations of the muscle (superficial vs. deep). If the difference were related to fiber type, then we might expect a different result if HRP was applied to superficial muscle fibers in a region of the myomeres where the red muscle is absent. Unfortunately some red muscle is present on most of the external surface of the myomeres, but it is much reduced in the ventral portion of the hypaxial musculature. In four animals, HRP was applied to only the superficial ventral portion of the hypaxial musculature on one side of the tail. In this region the layer of red muscle is very thin relative to the region near the lateral line (see Fig. 2), so both superficial red and superficial white fibers are exposed to HRP. On the opposite side of the tail, HRP was applied to both the superficial and the deep ventral portion of the hypaxial musculature.

Fig. 11. Motor axons in goldfish. A, C, and $\mathrm{E}$ are transverse hemisections of spinal cord. In each, a star is within the central canal, an asterisk marks the Mauthner axon, and HRP-filled motor axons are indicated by solid arrows. B, D, and F show enlarged views of the labeled motor axons in A, $C$, and $E$, respectively. A,B. HRP-filled motor axons labeled by HRP placed deep in the white hypaxial muscle. The labeled axons form two groups. One group (upper arrow in A), located near the Mauthner axon, contains some very large axons and other smaller ones. The other, more lateral group (lower arrow in A), contains only small axons. C,D. A section from the same experiment as in $A$, but closer to the ventral root where the axons shown in A exit from the cord. The group of dorsomedial axons has moved ventrally to join the lateral group of small axons. The large axons are located at the dorsomedial side of the group of labeled axons (solid arrows) destined to exit in the root. E,F. Motor axons filled after applying HRP to only the medial ramus ( $M R v$ ) of the ventral root. The section in $\mathrm{E}$ is at approximately the same rostrocaudal position relative to the root containing the labeled axons as Figure A. Small axons in the lateral group (solid arrow) are labeled in E. The large motor axons (open arrows) near the Mauthner axon are not labeled. Bar in $A=50 \mu \mathrm{m}$ and also applies to $C$ and $E$. Bar in $B=50 \mu \mathrm{m}$ and also applies to $\mathrm{D}$ and $\mathrm{F}$.
In these experiments, the HRP-filled motoneurons on the two sides were spread throughout much of the mediolateral and dorsoventral extent of the column, and also had similar size distributions (not shown). The large dorsal motoneurons were labeled on both sides in all four experiments. Therefore, the difference observed between the motoneurons innervating the superficial red muscle and those innervating the deep white muscle was not simply a difference between the motoneurons innervating superficial and deep muscle fibers but was related to differences in fiber type.

In all of the previous experiments whenever the deep white muscle was labeled, the superficial muscle was also labeled. Although it is clear from those experiments that the larger motoneurons innervate deep white muscle and do not innervate the superficial red muscle, the smaller labeled motoneurons might innervate only the superficial muscle or both superficial and deep muscle. In order to label the motoneurons innervating the deep white muscle on one side of the tail without passing through any superficial muscle, in seven animals HRP-soaked pledgets were passed through the superficial red and deep white epaxial $(\mathrm{N}=4)$ or hypaxial $(\mathrm{N}=3)$ muscle on one side of the tail into the deep white epaxial or hypaxial muscle on the opposite side.

Figure 16 shows summary diagrams of the results from two representative cases, both epaxial. The results from hypaxial experiments were similar. Labeled motoneurons on both sides of the cord were spread throughout much of the mediolateral and dorsoventral extent of the motor column. The size distributions from six of these experiments are shown in Figure 17. The distributions from the sides where both red muscle and white muscle were labeled were similar to those from other red-plus-white-muscle labeling experiments, with a large population of small cells and a tail of larger cells. On the side where only white muscle was labeled, small and large motoneurons throughout the range of sizes of motoneurons were filled, even when only relatively few cells were labeled. These distributions did not have the relatively large number of smaller motoneurons present when both red muscle and white muscle were labeled, suggesting that some of the smaller motoneurons filled by passing HRP through the red muscle were not labeled when the HRP was restricted to the white.

The small motoneurons filled on the white muscle side of the cord probably innervate the deep white muscle. The most plausible alternative explanation is that the axons of small motoneurons were inadvertently labeled where they pass through white muscle to reach other muscle. Most, if not all, of the axons from small motoneurons destined for the superficial red muscle near the lateral line probably travel in the medial ramus of the ventral root (MRv), which runs laterally in the horizontal septum. It is unlikely that these axons were labeled on the white muscle side, because the HRP was applied above or below the septum. Furthermore, some of the small motoneurons filled from white muscle had axons passing medial to the M-axon, unlike any filled from the medial ramus or from red muscle. Axons in the dorsal or ventral rami might have been la beled because these rami run deep in the musculature. Some axons in these rami probably supply the innervation of the muscles of the dorsal and anal fins. The dorsal fin is innervated by small motoneurons (unpublished observations); however, it is unlikely that the small motoneurons 

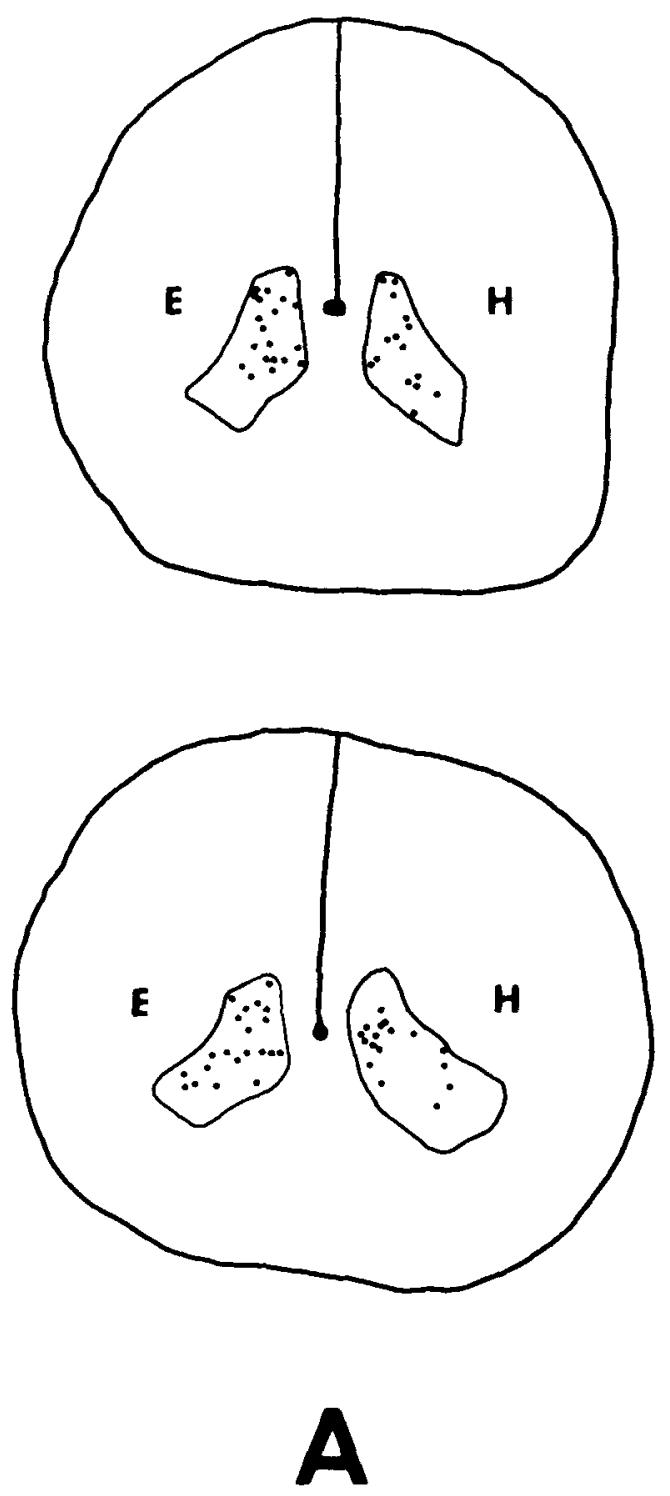

Fig. 12. Summary of the distribution of HRP-filled motoneurons in transverse sections of the spinal cords from two fish (A,B) in which the dorsal portion of the epaxial muscle was labeled with HRP on one side of the tail (E), and the ventral portion of the hypaxial muscle was labeled with HRP on the opposite side of the tail $(\mathrm{H})$. Two summary sections are shown for each experiment. Each summary section shows the position of HRP-filled

filled in the four epaxial through-the-tail experiments were those innervating the dorsal fin, because the experiments were performed well caudal to the dorsal fin, and the labeled small motoneurons did not occupy the position in the spinal cord typically occupied by motoneurons innervating the dorsal fin. The only other alternative explanation of the labeling of small motoneurons is that they do not innervate the deep white muscle, but rather their axons travel in the dorsal and ventral ramus and they innervate the more superficial white muscle. This last possibility is difficult to rule out.

In summary, different populations of motoneurons innervate red and white muscle. The red muscle near the lateral line is innervated only by small motoneurons in the ventral portion of the motor column. Their axons pass lateral
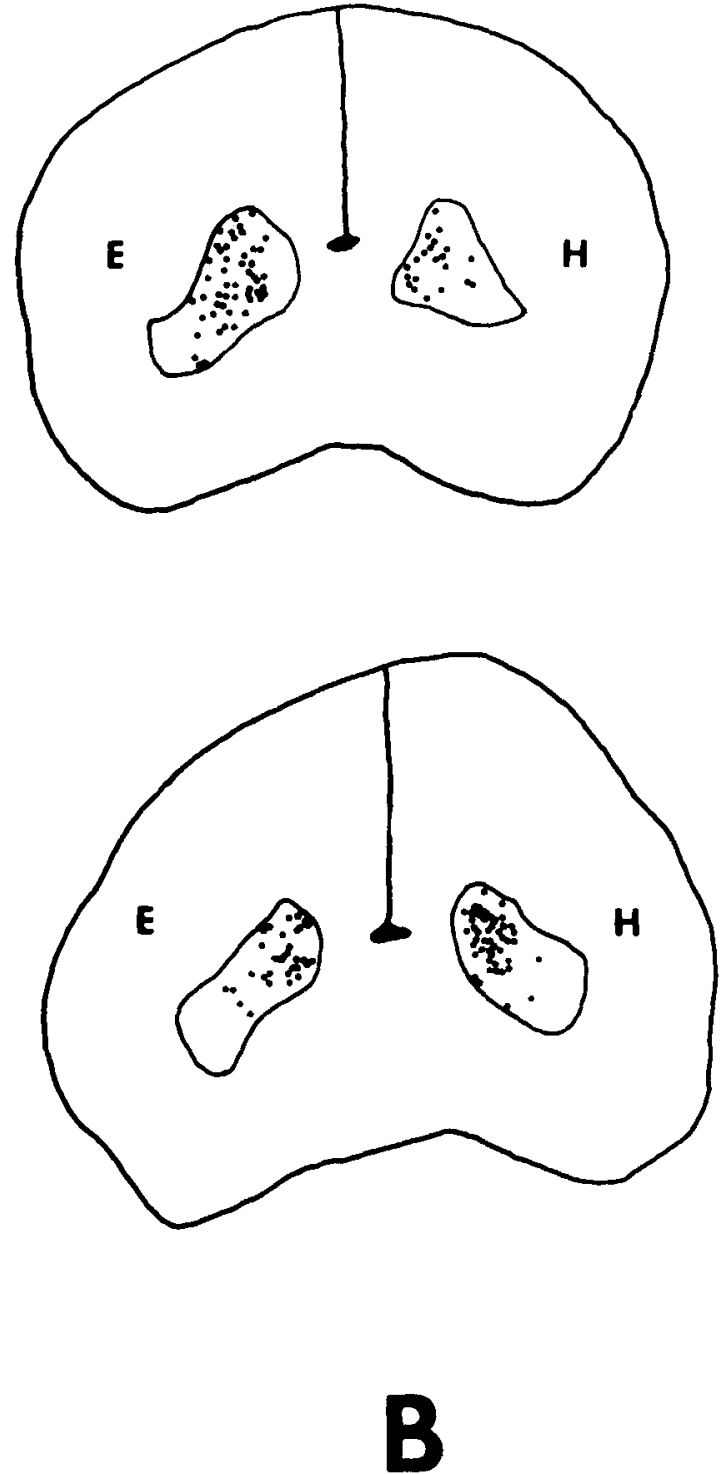

motoneurons from a series of frozen sections. The bottom section of each pair shows the distribution of labeled cells from the rostral portion of the sections containing labeled cells, while the top section shows the distribution of more caudal cells. HRP-filled cells are represented by black dots within an outline of the medial motor column (based on the positions of labeled and unlabeled cells).

to the $\mathrm{M}$-axon and travel in the medial ramus of the ventral root. The white muscle is innervated by a population of large motoneurons in the dorsal portion of the motor column that do not innervate red. Their large axons pass medial to the M-axon in the cord and travel only in the dorsal and ventral rami of the root. The white muscle is probably also innervated by smaller, ventral motoneurons similar to those innervating red muscle; however, some of these smaller motoneurons may have been filled because their axons passed through the deep white muscle without terminating there.

\section{Necturus}

Musculature. The musculature on the tail of mudpuppies was examined by gross dissection. Like the musculature in goldfish, it was formed by a series of myomeres 

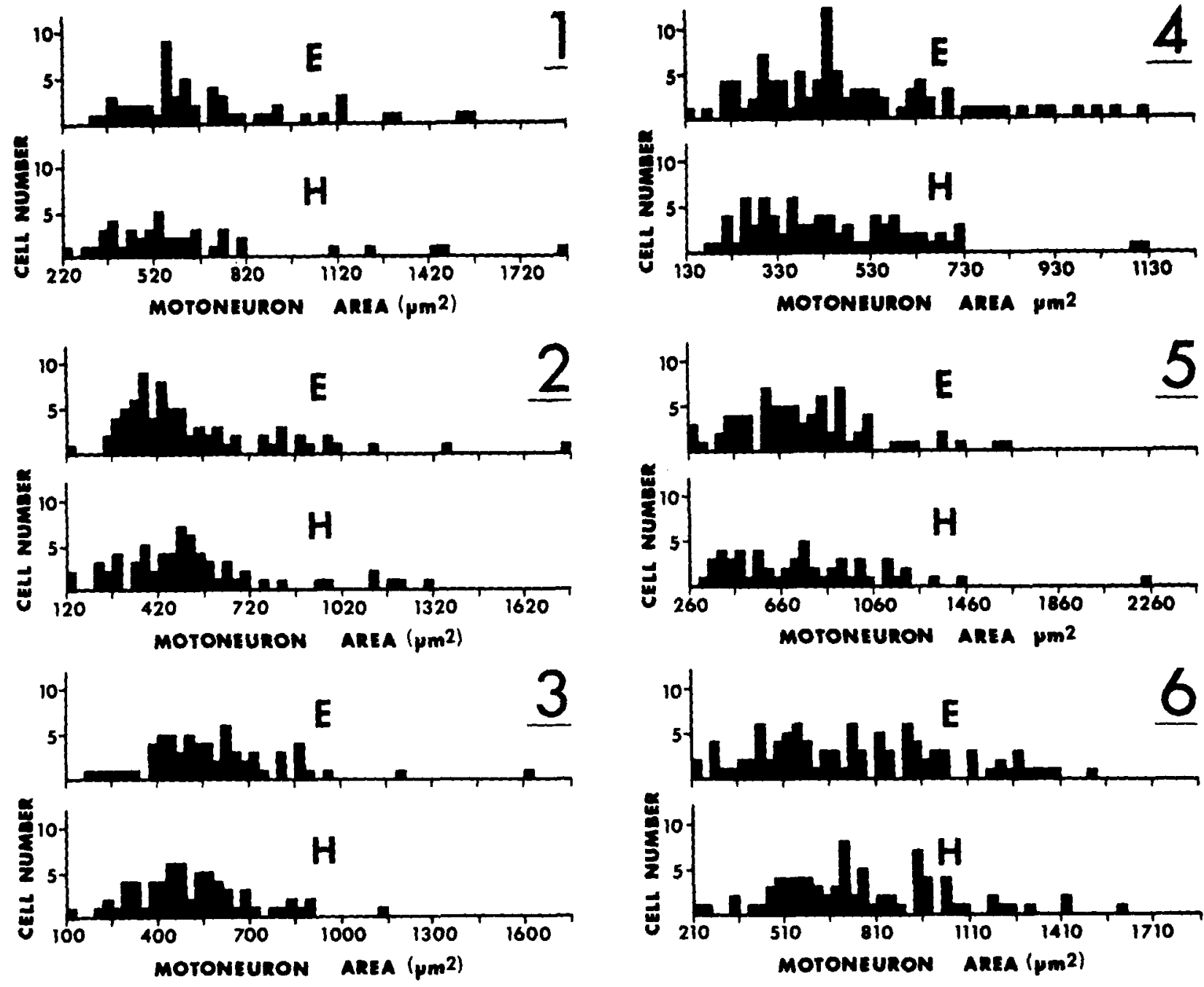

Fig. 13. The size distributions of the cross sectional areas of HRP-filled motoneurons from six experiments $(1-6)$ in which the dorsal portion of the epaxial muscle was labeled with HRP on one side of a fish (E), and the ventral portion of the hypaxial muscle was labeled on the opposite side of

separated from one another by myosepta (Fig. 18A). The myomeres were slightly folded, but not nearly as much as those of most fishes (Bone, '78). The majority of the muscle fibers ran from myoseptum to myoseptum; however, some of the deeper fibers attached to vertebrae.

Spinal nerves. The dorsal and ventral roots of spinal nerves on the tail arose from the spinal cord and ran caudally for several millimeters before exiting from the vertebral canal. Just outside of the canal they joined at a large spinal ganglion from which two major branches, a dorsal and ventral ramus (Fig. 18B), arose and ran caudally, branching into the epaxial and hypaxial portions of the musculature, respectively. The branching patterns of the rami were irregular, in agreement with the observations of Nishi ('16); the details varied from segment to segment and between different animals. Usually some branches ran laterally toward the superficial portions of the myomeres while others ran dorsally or ventrally deep in the myomeres. the fish (H). Pairs 2, 3, 4, 5, and 6 are not significantly different. The histograms in pair number 1 are barely significantly different the epaxial one is larger).

Medial motor column. The locations and morphologies of HRP-filled motoneurons were examined in transverse sections of spinal cords from 16 animals in which axial muscle or spinal nerves were exposed to HRP. Although most of the experiments were performed on the tail, motoneurons filled by HRP applied to muscle or nerves on the trunk occupied similar positions in the spinal cord, and were similar morphologically to those innervating tail musculature. In the following sections I deal only with motoneurons from the tail.

The spinal cord of Necturus was flattened, with the gray matter extending laterally and only slightly ventrally from the central canal (Fig. 19A,C). The ventral horns were well developed; however, the dorsal horns were very small. The central canal was surrounded by a thick ependymal layer (Figs. 19A, 20B). The motoneurons, indicated by black dots in the reconstruction shown in Figure 22B, were located in a band extending from the extreme ventrolateral tip of the ventral horn along its entire ventral edge to a region 

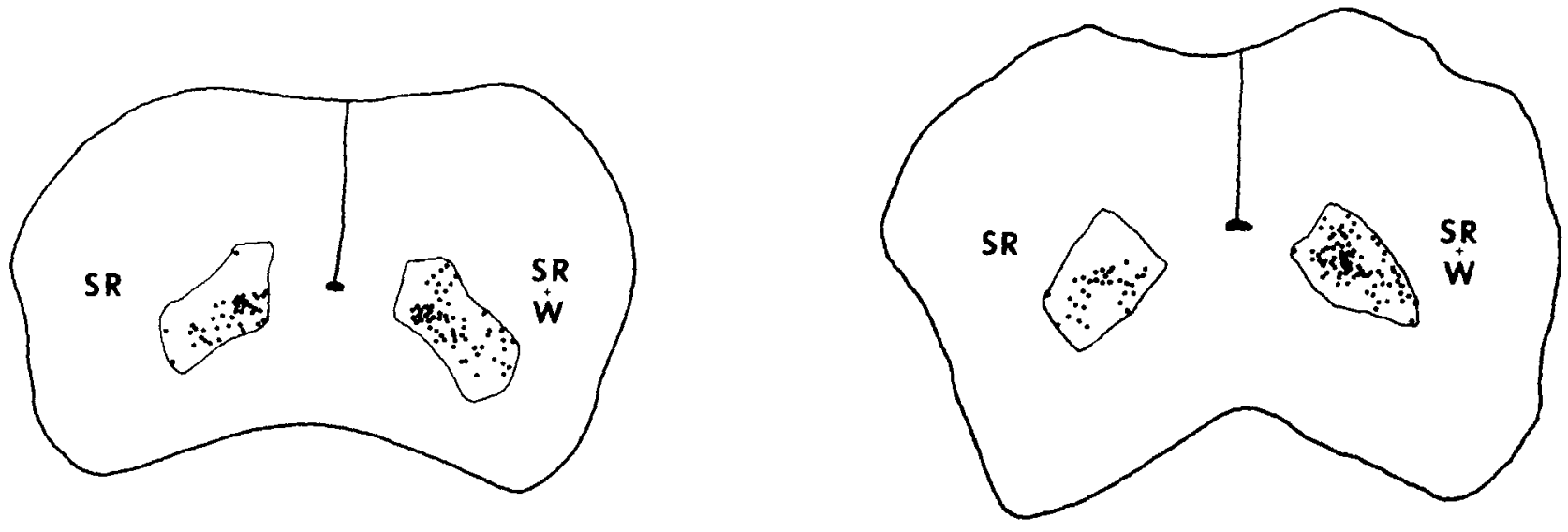

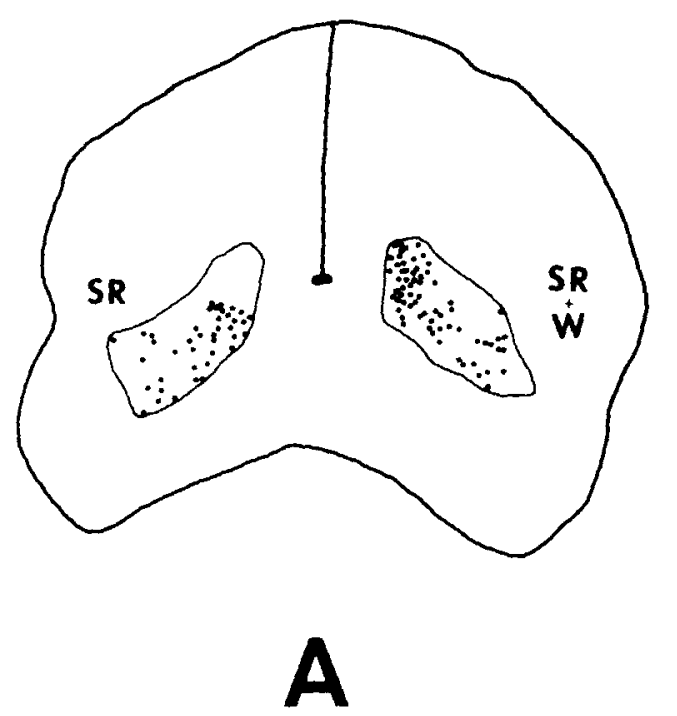

Fig. 14. Summary of the distribution of HRP-filled motoneurons in transverse sections of the spinal cords from two fish ( $A$ and $B$ ) in which both the superficial red and deep white muscle were labeled with HRP on one side of adjacent to the ependymal layer surrounding the central canal. Motoneurons in different mediolateral locations in the motor column had different morphologies. Below I describe them, beginning with those in the lateral part of the column and proceeding medially.

Motoneurons. The largest motoneurons were located at the ventrolateral tip of the ventral horn. HRP-filled examples of these are shown in Figures 19A,B and 20A. These were large (some were 40-50- $\mu$ m diameter) multipolar cells with tremendous dendritic arbors spread over much of the ipsilateral white matter from a region dorsally near processes from the dorsal root, around the ventral horn, and into the white matter below the central canal (Fig. 19A,B). The dendrites in the dorsal and lateral white matter radiated from the cell body and sometimes reached the peripheral edge of the spinal cord. Dendritic processes ventral to the ventral horn arose from a large dendrite, indicated by an arrow in Figure 19A, which ran medially along the ventromedial edge of the gray matter. The axons of some of these motoneurons were traced in serial sections, and they arose from this medial process.

The majority of motoneurons lay along the ventral side of the gray matter and were generally smaller than the more lateral ones. Most were located on the ventral edge of the lateral portion of the ventral horn. Examples are shown in Figures 19C,D and 20A. These were unipolar, comet-shaped cells with their major dendrite running laterally and dorsally around the ventrolateral edge of the ventral horn. Dendritic processes arising from this main trunk ramified in the ventral and lateral regions of the ipsilateral white matter. Others occasionally crossed below the central canal into the contralateral side of the cord (solid arrows in Fig. 20B).

Those motoneurons located near the central canal, in the medial portion of the ventral horn (Fig. 20C), were relatively simple, rounded cells with a few dendritic processes 

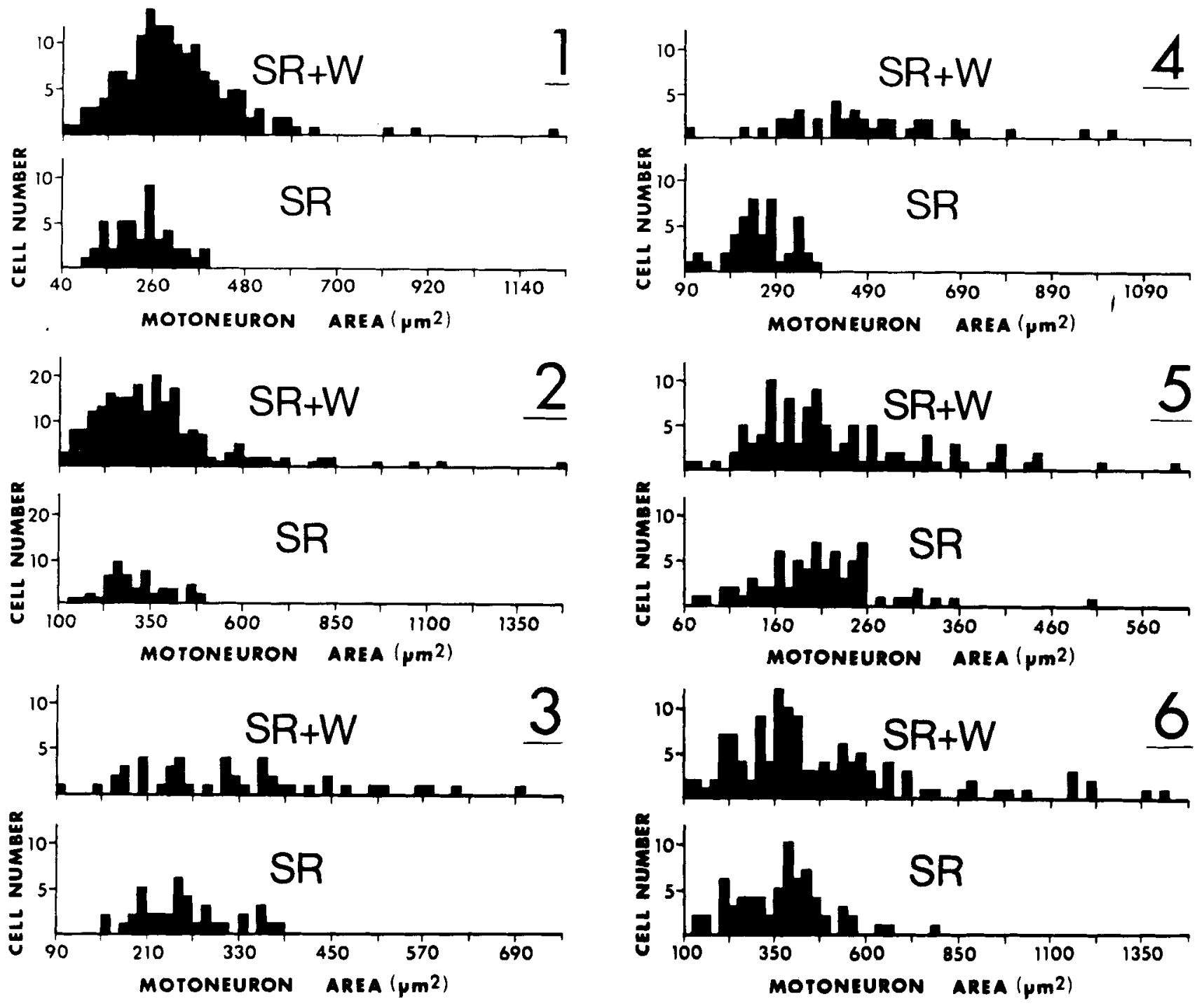

Fig. 15. The size distributions of the cross-sectional area of HRP-filled motoneurons from six experiments (16 ) in which both red and white muscle were labeled on one side of a fish (SR $+\mathrm{W}$ ) and only red muscle was labeled on the opposite side of the same fish (SR). Pairs 1,3,4, and 6 are significantly different, and pairs 2 and 5 are not.

running medially or laterally along the ventral edge of the ventral horn. The most medial cells in the motor column, indicated by an arrow in Figure 20D, were adjacent to the ependymal layer surrounding the central canal. These cells were very simple and lacked dendritic processes. Generally, relatively few of these medial cells were filled.

In summary, the motoneurons lay along the entire ventral edge of the ventral horn, from its lateral tip to the ependymal layer. Their morphology was correlated with their position in the column; large multipolar cells occupied the extreme lateral tip, unipolar ones were located medial to these, and the motoneurons in the extreme medial part of the column were very simple, with few or no dendritic processes.

Motor axons. To determine the trajectory of motor axons in the cord I examined axons filled from 30 experiments in which entire ventral roots or branches of ventral roots were exposed to HRP. Figure 21A shows a transverse section through a spinal cord rostral to a ventral root which was exposed to HRP. The labeled motor axons, indicated by open arrows, form an L-shaped group with the top part of the $L$ adjacent to the ventrolateral side of the ependymal layer and its base lying along the ventrolateral border of the cord. A group of a few, about 14, relatively large axons occupied the region adjacent to the ependymal layer. The majority of filled axons were smaller and were located ventral to the large ones. Closer to the root all of the axons occupied the ventral edge of the cord, with the large ones lying on the medial side of the group destined to exit the root (Fig. 21C). Generally, axons were not easily associated with motoneurons because the two did not appear in the same section. However, a few of the large axons were successfully traced in serial sections, and they arose from the very large motoneurons located in the extreme lateral part of the motor column.

Motoneurons were rostral to the root containing their axons, which often had long caudal trajectories within the cord. Figure 23 , dealt with again in a later section, shows 

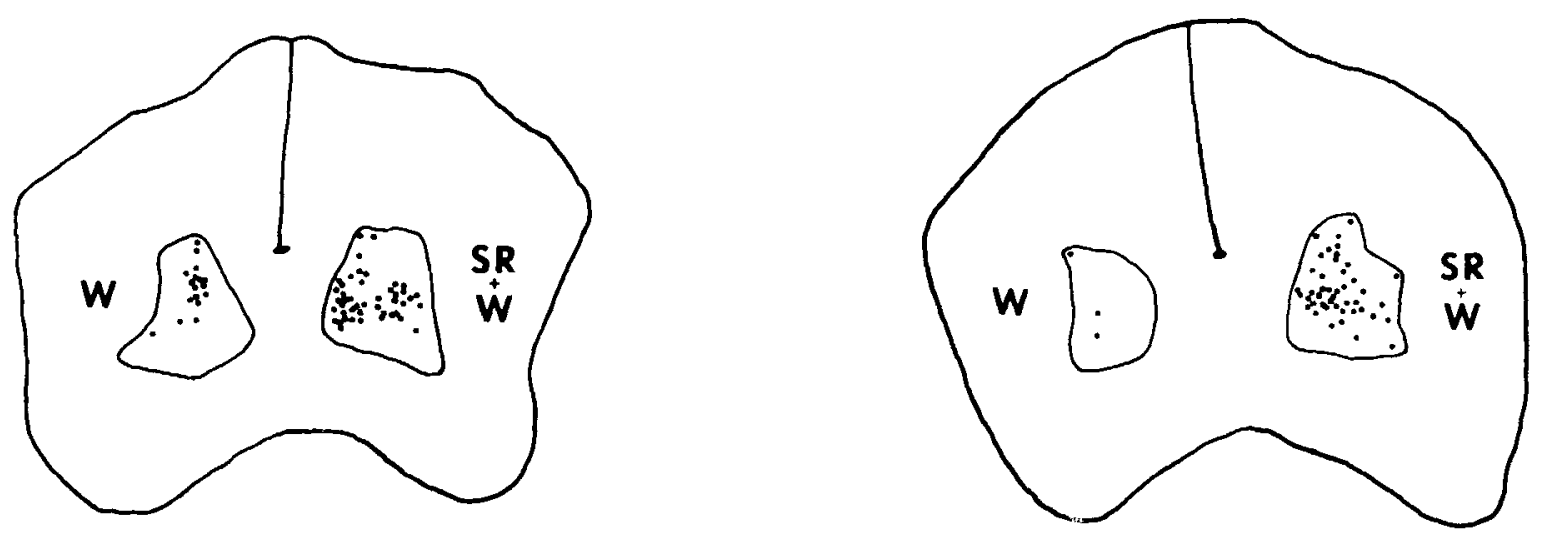
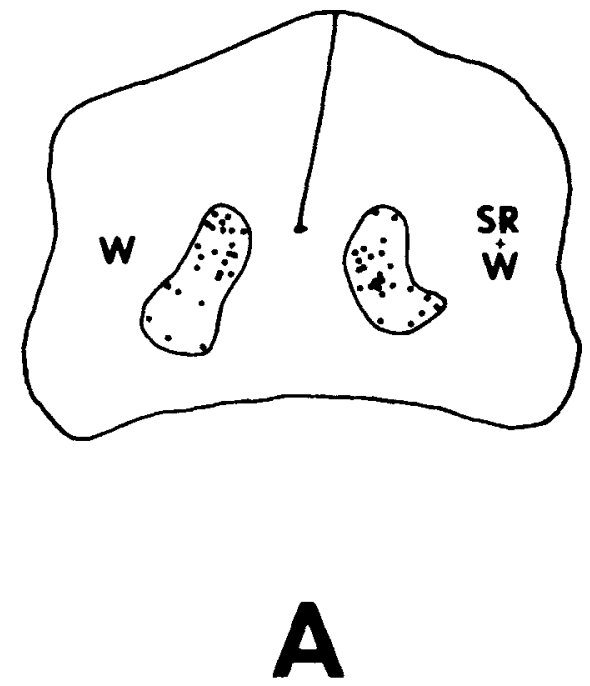

Fig. 16. Summary of the distribution of HRP-filled motoneurons in transverse sections of the spinal cords from two fish (A and $B$ ) in which HRP soaked Gelfoam was passed through the tail to label both superificial red and deep white muscle on one side of the tail $(S R+W)$, and only white muscle on the opposite side (W). The conventions used for the reconstructions are like those in Figure 12 two histograms representing the longitudinal distributions of HRP-filled motoneurons relative to the root in which their axons exit from the cord. The most rostral motoneurons were usually located between the first and second root rostral to the one containing their axons (Fig. 23); however, in one case a few motoneurons were slightly more than two segments rostral. Thus, some motor axons bypassed one or two roots before exiting from the cord.

Some of the early studies of motoneurons innervating axial muscle in urodeles and other anamniotic vertebrates (Coghill, '13, '26; Youngstrom, '38, '40; Whiting, '48) indicated that motor axons arose as collaterals of processes that remained in the ventral part of the cord and extended caudally beyond the root at which the axons exited. The selective labeling of ventral roots or branches of spinal nerves with HRP allows a direct experimental evaluation of these observations. In the 30 cases examined, two classes of results were obtained. In 24 of them no labeled processes extended caudally along the ventral side of the cord beyond the root from which they were filled; an example is shown in Figure 21D. In the other six cases a few (one to ten) processes bypassed the root of a labeled segment to exit in a more caudal root. There are two, equally plausible, inter pretations of these processes. If motoneurons project axons into multiple ventral roots, as some do in Xenopus embryos (Roberts and Clarke, '82), then labeling one root would fill processes in another, and these might look like the caudal processes I observed. Alternatively, the caudal processes may represent axons that were exposed to HRP in a more caudal nerve. Regardless of their interpretation these caudal processes were very rare and always exited in a ventral root. I conclude that motor axons do not arise as collaterals 

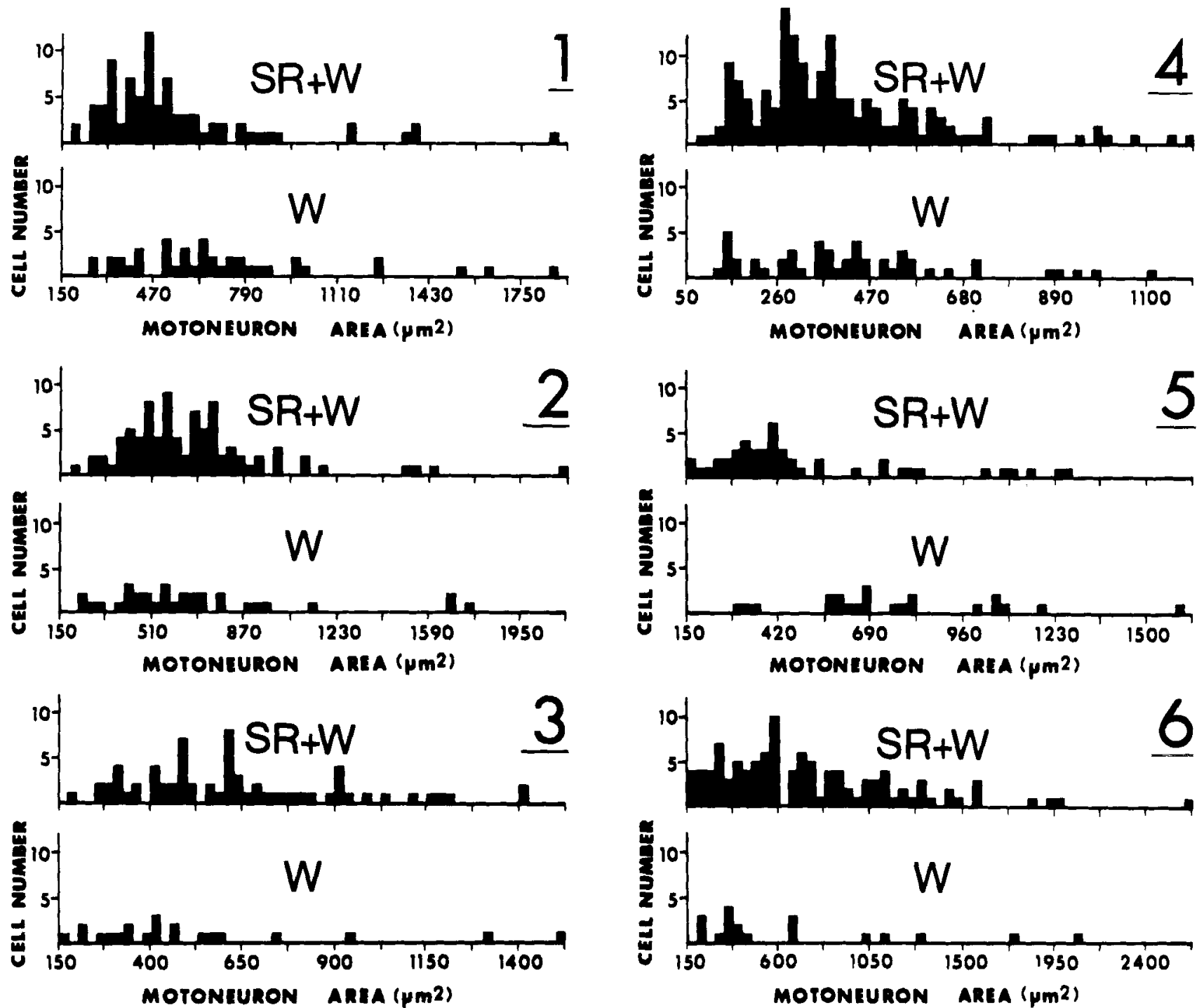

Fig. 17. The size distributions of the cross-sectional area of HRP-filled motoneurons from six (1-6) experiments in which HRP-soaked Gelfoam was passed through the tail of a fish to label both red and white muscle on one side of the fish (SR $+W$ ) and only white muscle on the opposite side (W).

of caudal processes that remain in the cord.

In summary, there were large and small motor axons. The large ones were grouped together, and they arose from large lateral motoneurons. The more numerous, smaller axons probably arose from the more numerous, smaller motoneurons located along the ventral edge of the ventral horn. Some axons in both size classes ran longitudinally, caudally, for long distances in the cord, sometimes bypassing a ventral root before exiting. Axons entering a ventral root did not arise as collaterals of processes continuing caudally in the cord.

Dorsal ramus/ventral ramus. The dorsal and ventral rami in Necturus were separately exposed to HRP to compare the internal organization of the motor column with the motor columns in other vertebrates. Figure 22 shows representative reconstructions of the locations, in transverse sections of the cord, of motoneurons that were filled by HRP applied to branches of the dorsal (Fig. 22A) or ventral (Fig. 22B) rami. Motoneurons filled from the dorsal ramus were located in the lateral part of the motor column. They included large multipolar cells at the extreme lateral tip of the ventral horn as well as smaller unipolar ones along its ventrolateral edge. The majority of motoneurons filled from the ventral ramus (Fig. 22B) were located in positions similar to those occupied by dorsal ramus motoneurons. However, some of the ventral ramus motoneurons were located in the medial part of the column, adjacent to the ependymal layer. Although relatively few cells near the ependymal layer were labeled, they were only filled from the ventral ramus, not the dorsal one. This is somewhat different from goldfish, in which even such minor differences in the locations of epaxial and hypaxial motoneurons were not evident.

When the dorsal and ventral rami from labeled segments were removed, sectioned, and treated for HRP, labeled axons were found only in the ramus exposed to HRP, not 


\section{A}

\section{DORSAL}
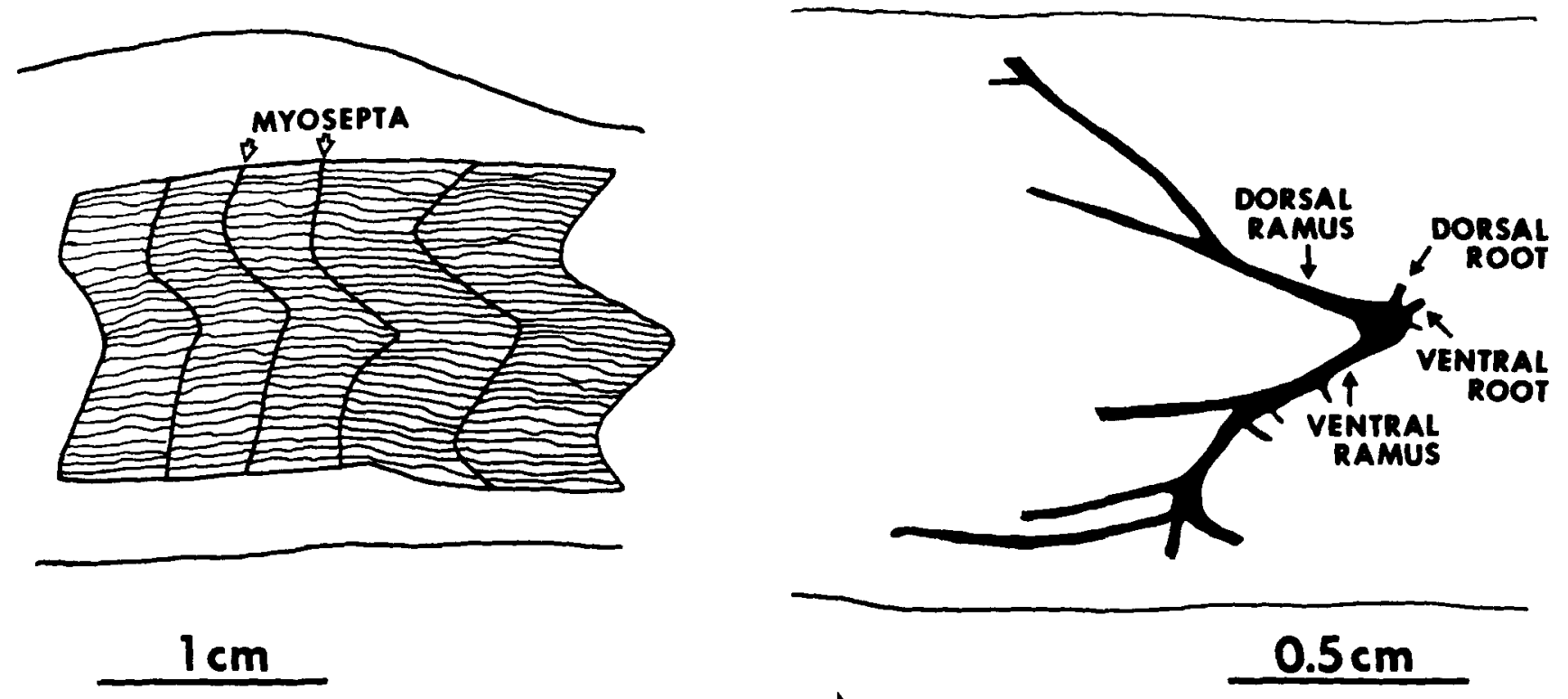

ROSTRAL

Fig, 18. Diagrams of the musculature (A) and a spinal nerve (B) from the tail of Necturus. A. A camera lucida tracing of a lateral view of the myomeres from the tail of Necturus (190-mm snout-vent length) after removal of the skin. The axial muscle is divided transversely into myomeres by connective tissue myosepta. The muscle fibers run from myoseptum to

in the other ramus. Therefore, the similarities in the populations of labeled motoneurons observed after applying HRP to individual rami were not attributable to the inadvertent exposure of both rami to HRP.

The overlap, along the rostrocaudal axis of the cord, of motoneurons with axons in the two rami, was assessed by labeling dorsal and ventral rami of the same segment on opposite sides of the body. Figure 23 shows histograms representing the longitudinal distributions of motoneurons filled in one typical experiment. Motoneurons filled from the two rami overlapped substantially along the rostrocaudal axis of the cord. However, the longitudinal distribution of motoneurons labeled from the dorsal ramus was consistently shifted slightly rostrally relative to the distribution from the ventral ramus.

The similarities in the populations of motoneurons filled from the two rami were also evident in the labeled motor axons. Figure 21B shows HRP-filled axons from an animal in which a branch of the dorsal ramus was labeled on the left and a branch of the ventral ramus of the same segment was labeled on the right. On the left, the axons form two widely separate groups of large dorsal and smaller ventral axons. Both large and small axons are also filled on the right, but the two groups are closer together, and the small axons are located in a region corresponding to the gap between the large and small axons on the left. Closer to the root (Fig. 21C) the axons filled from the dorsal or ventral rami are located ventrally, and within the root (Fig. 21D) they are sometimes confined to one side. myoseptum. The lines above and below the myomeres indicate the outline of the tail, which extends beyond the musculature dorsally and ventrally. B. A camera lucida tracing of a spinal nerve from the tail of Necturus (185$\mathrm{mm}$ snout-vent length). The horizontal lines indicate the dorsal and ventral extent of the musculature.

In summary, the motoneurons filled from the dorsal and ventral rami were mostly similar. Their cell bodies and axons had similar size distributions (not shown), and their locations overlapped extensively in the transverse and longitudinal extent of the motor column. However, there were some consistent differences; motoneurons filled from the dorsal ramus were, on average, slightly rostral to those filled from the ventral ramus, and the most medial motoneurons in the column were only filled from the ventral ramus.

\section{DISCUSSION \\ Primary and secondary motoneurons}

A common picture of the organization of the medial motor column of anamniotes is emerging from recent studies of fish and amphibians. Two major classes of motoneurons have been identified in the motor columns of embryonic or larval agnathans (Whiting, '48), fishes (Myers, '85), urodeles (Coghill, '13; Youngstrom, '40; Blight, '78; Carey, '83; Stephens and Holder, '85), and anuran tadpoles (Hughes, '59; Forehand and Farel, '82; Nordlander, '84). One class is formed by a relatively small number of large multipolar cells with extensive dendritic arbors and large axons in association with the Mauthner axon. Electrophysiological studies in anuran tadpoles (Lee, '82) and adult teleost fish (Yasargil and Diamond, '68; Diamond, '71) suggest that these cells receive a monosynaptic connection from the Mauthner axon and are very important in the generation of the startle response initiated by the Mauthner cell. The 

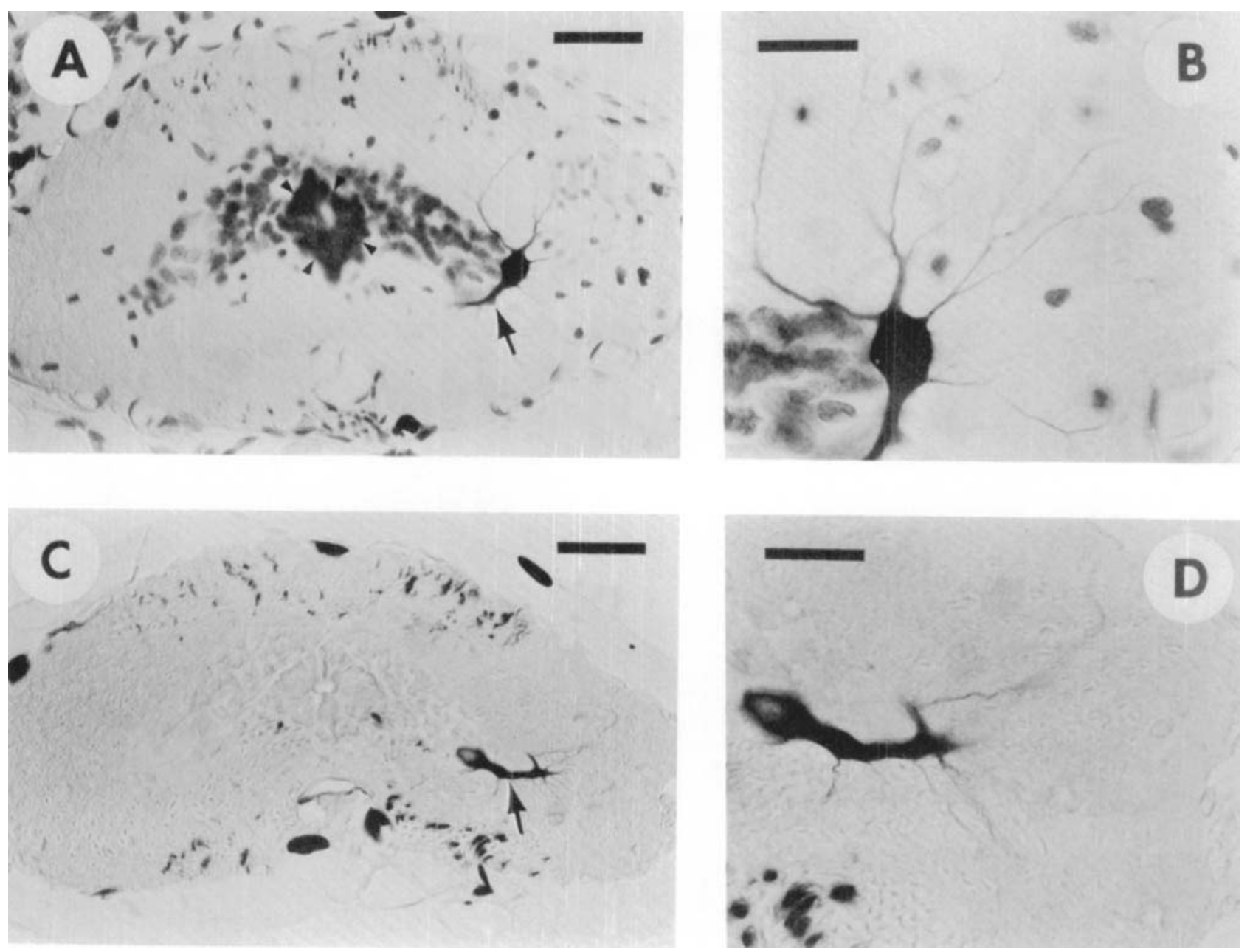

Fig. 19. Morphology of multipolar and unipolar motoneurons in the spinal cord of Necturus. A. A cross section of the spinal cord from the tail counterstained with methyl green. Cells surrounding the ependymal layer are outlined by arrowheads. A large multipolar HRP.filled motoneuron is located at the tip of the ventral horn on the right side of the panel. A process (arrow) from the motoneuron, which gives rise to the axon, runs around the ventral side of the ventral horn (bar $=100 \mu \mathrm{m}$ ). The dendrites of the motoneuron, shown in higher magnification in $B$, ramify throughout much of

the ipsilateral white matter (bar $=50 \mu \mathrm{m}$ ). C. A cross section (not counterstained) of the spinal cord showing a unipolar motoneuron along the ventrolateral edge of the gray matter on the right side of the panel (bar $=100 \mu \mathrm{m}$ ). The major dendrite of this motoneuron (arrow), shown at higher magnification in panel $\mathrm{D}$, runs laterally around the ventral and lateral edges of the ventral horn. Smaller dendritic processes extend from the main trunk into the ipsilateral white matter $(\mathrm{bar}=50 \mu \mathrm{m})$.

other class of motoneurons is comprised of smaller, more abundant, mostly unipolar cells, which are spatially segregated from the class of large motoneurons. These small cells typically have smaller dendritic arbors than the large ones, and their axons run directly to the ventral root without any direct association with the M-axon. Developmental studies in urodeles (Coghill, '19, '26; Youngstrom, '40; F. Carey, personal communication), anuran tadpoles (Forehand and Farel, '82; Nordlander, '84), and teleost fish (Myers, '83) indicate that the class of large cells is formed by the first motoneurons to develop; consequently, they have been called primary motoneurons. The class of smaller cells develops later than primary motoneurons, and the cells in this class have been referred to as secondary motoneurons (Coghill, '26; Youngstrom, '40; Forehand and Farel, '82; Myers, '83).
Cells having the morphological characteristics of primary and secondary motoneurons are present in both goldfish and mudpuppies. The large, dorsal motoneurons in goldfish are similar to both primary motoneurons identified in embryos and larvae of zebrafish (Eisen et al., '84; Myers, '85), and a class of large motoneurons in postmetamorphic zebrafish (van Raamsdonk et al., '83). These primary motoneurons are more abundant in goldfish, where there are roughly 8-12 per body segment, in contrast to the two to four in zebrafish. Adult goldfish are larger than zebrafish, and the differences in the number of motoneurons may simply reflect the size difference. The more abundant, smaller, ventral motoneurons in goldfish are similar to secondary motoneurons identified in developmental studies.

The distinction between primary and secondary motoneurons is, strictly speaking, developmental; primary ones dif- 

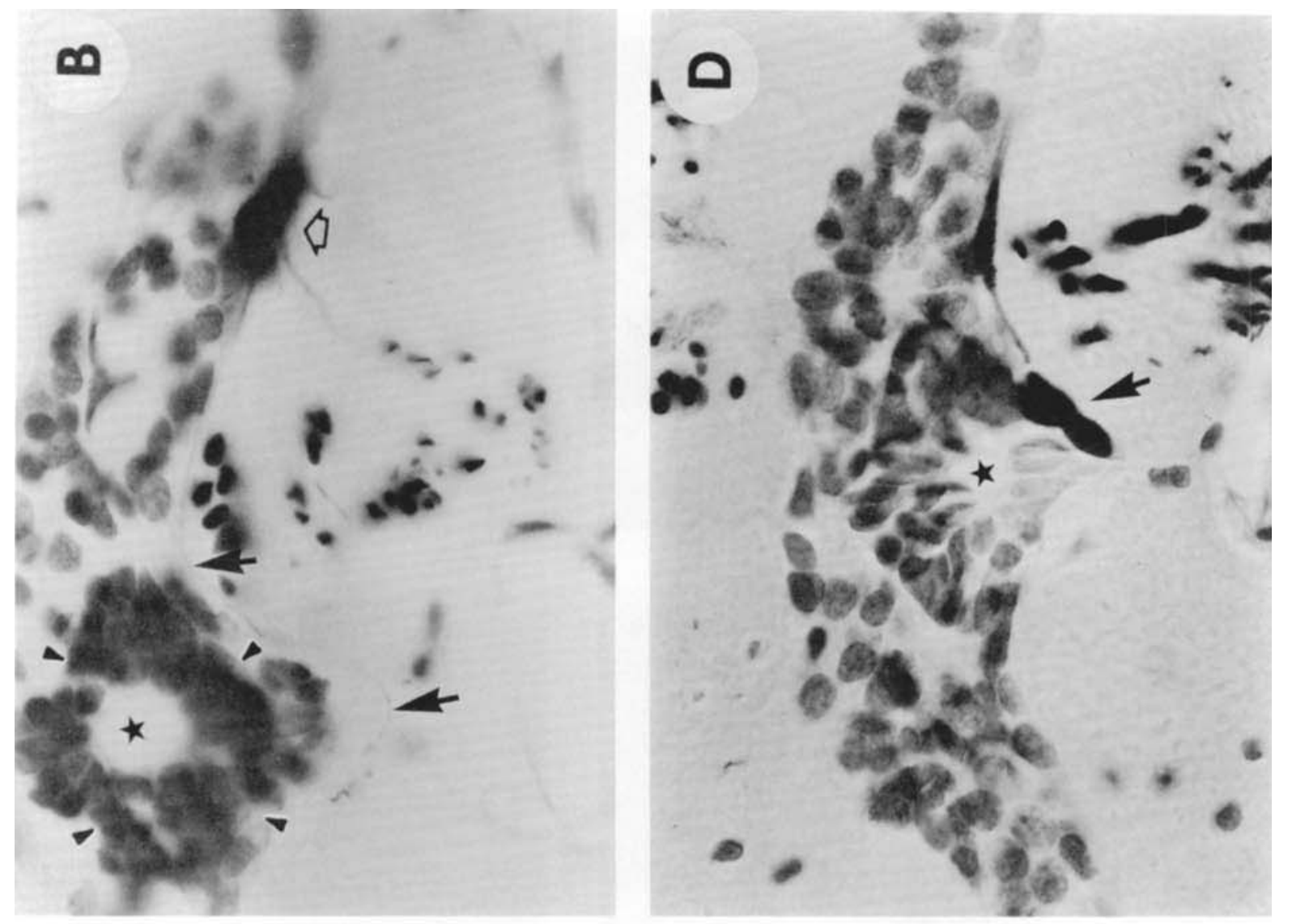

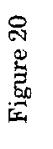
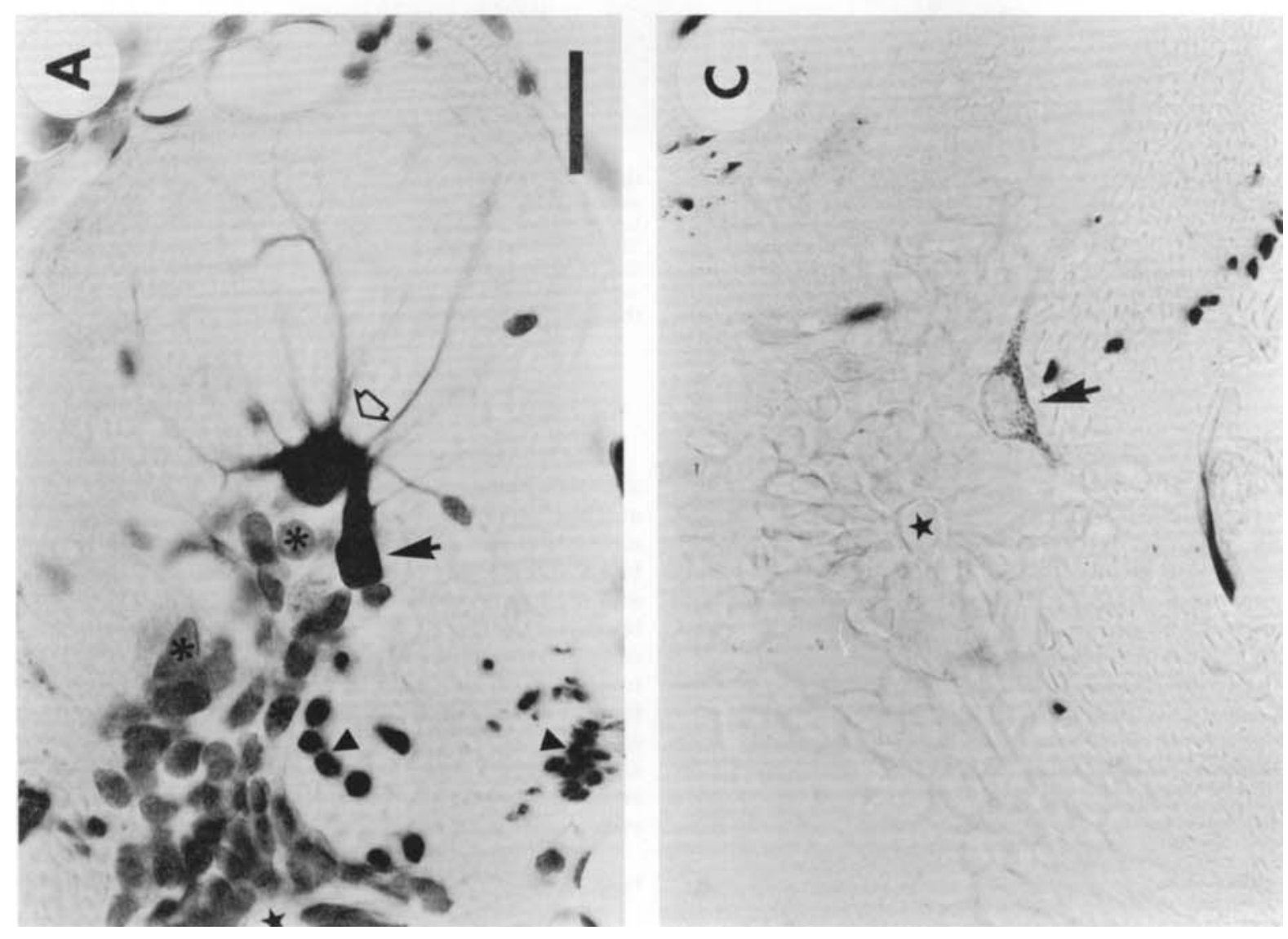


\section{MOTONEURONS IN GOLDFISH AND MUDPUPPIES}

ferentiate before secondary ones. Because the relationship between motoneurons innervating axial musculature in embryonic or larval fishes and those present in postmetamorphic adults is unknown, the identification of primary and secondary neurons in adults is somewhat tentative. Nevertheless, given the relatively minor changes that occur during metamorphosis in many teleost fish, the motoneurons in adult fish are most likely the same populations of motoneurons identified as primary and secondary motoneurons in embryos and larvae.

Mudpuppies are paedomorphic salamanders that never undergo metamorphosis (Conant, '75); consequently, their motoneurons are directly comparable to motoneurons identified in larval stages of other salamanders. The relatively large multipolar motoneurons located in the extreme lateral portion of the ventral horn of Necturus are morphologically similar to the primary motoneurons of other anamniotes. The large axons arising from these cells are grouped together in the spinal cord and run in the medial portion of the group of axons destined to exit in a ventral root. A very similar grouping of large axons, arising from primary motoneurons, is evident in the spinal cord of goldfish in which the large axons occupy the same position as those in Necturus, relative to the smaller axons within the group of axons exiting in a ventral root. In other anamniotes, including goldfish, the axons of primary motoneurons are associated with the Mauthner axon. The relationship between the two in Necturus is unknown, because the Mauthner axons are not recognizable in either frozen or semithin sections of the spinal cord from the tail of Necturus. Mudpuppies have Mauthner cells (Zottoli, '78), but the axons in the region of the tail are not as distinctive morphologically as they are in some fishes. The smaller, unipolar motoneurons located on the ventrolateral edge of the ventral horn in Necturus are morphologically similar to the secondary motoneurons identified in other anamniotes.

The axons of primary and secondary motoneurons in mudpuppies and goldfish clearly do not arise as collaterals of processes continuing caudally that remain in the spinal cord. In nearly all cases in which nerves were exposed to HRP, no HRP-filled processes extended caudally in the ventral part of the cord beyond the ventral root of the labeled segment. In the few cases in which processes bypassed a labeled root in Necturus, they did not remain in the cord; they exited in a more caudal root.

The absence of these caudal processes is significant because of the important role that they played in some previous accounts of the motor systems of anamniotes. Coghill's (13) initial description of primary motoneurons in Ambystoma indicated that their axons arose as a collateral of a process that continued to run caudally in the spinal cord to

Fig. 20. Examples of HRP-filled motoneurons in different portions of the motor column of Necturus. All panels show cross sections of the spinal cord from the tail, and a star marks the central canal in each. A, B, and D show counterstained sections. A. Multipolar (open arrow) and unipolar (solid arrow) motoneurons located in the lateral portion of the ventral horn. Other solid black profiles (indicated by arrowheads) are HRP-filled motor axons; lighter profiles (asterisks) are counterstained nuclei. B. A small dendrite (solid arrows) from a ventrolateral cell (open arrow, not in the plane of focus) crosses to the contralateral side of the ventral horn ventral to the central canal. Arrowheads outline cells surrounding the ependymal layer. C. A motoneuron (arrow) near the central canal, adjacent to the ependymal layer. $D$. Two motoneurons (arrow) located subependymally. Bar in panel $\mathrm{A}=50$ $\mu \mathrm{m}$ and also applies to $\mathrm{B}-\mathrm{D}$. contact the dendrites of more caudal motoneurons. In his opinion, these interconnections of rostral and caudal motoneurons transmitted an excitatory wave that ran caudally along the body. His observations strongly influenced subsequent studies of the motor columns in other anamniotic vertebrates and Branchiostoma, many of which reported that the axons of primary motoneurons arose as collaterals of a process that continued caudally in the "ventral motor tract" of the spinal cord (Youngstrom, '38, '40; Whiting, '48; Bone, '60). These collaterals have generally not been observed in more recent studies of the motor columns (Blight, '78; Roberts and Clarke, ' 82 ; but see Nordlander, ' 84 ); therefore, the motor scheme proposed by Coghill, and most recently presented in an account of the evolution of the nervous system (Sarnat and Netsky, '81), seems unlikely.

The motoneurons sending axons into adjacent ventral roots in Necturus overlap more extensively along the rostrocaudal axis of the cord than those in many other vertebrates. Motoneurons are typically spread over two, and, rarely, three segments rostral to the root in which their axons exit from the cord; in many other vertebrates including goldfish (Smith and Hollyday, '83; Fetcho, '86), they are not more than one segment rostral or caudal to the root. If the substantial longitudinal overlap of motoneurons in $\mathrm{Nec}$ turus is also present in Ambystoma, then it may explain the apparent collateral origin of the motor axons observed by Coghill ('26) and Youngstrom ('40). In the tangle of processes visible in their silver-stained preparations, axons exiting in a ventral root might easily have appeared to arise from the axons of other motoneurons that bypassed the root to exit in a more caudal one. Alternatively, Roberts and Clarke ('82) reported that motoneurons occasionally send axons out two ventral roots in Xenopus embryos, and though these were rare, motoneurons like these might also account for some of the observations by Coghill and Youngstrom.

\section{Medial cells in Necturus}

The relatively simple labeled motoneurons located adjacent to the ependymal layer in Necturus are puzzling. Similar motoneurons have not been reported in any published studies of the motor column of urodeles, though they have been observed in some recent HRP studies of motoneurons innervating limb muscles ( $F$. Carey, personal communication). These labeled cells are probably not preganglionic autonomic neurons, because the labeling experiments were performed on the tail where preganglionic cells should be absent. Furthermore, some of the medial cells were filled even when the nerve branches were labeled far distally in the musculature. Even if preganglionic cells were present in the tail, one would not expect to label them in the distal musculature, because only postganglionic axons should be there.

The relatively undifferentiated morphology of the medial cells suggests that they may be newly differentiated. Newly born motoneurons in other vertebrates (Farel and Bemelmans, '80; Moody and Heaton, '81) send axons out to the periphery before they have differentiated fully and before they have migrated to their final location in the motor column. The medial cells in Necturus may be newly born cells in the process of migration laterally along the ventral side of the ventral horn. If they are new motoneurons, it is odd that they project only into the ventral ramus. An eval uation of this possibility must await birth-dating studies with tritiated thymidine. 

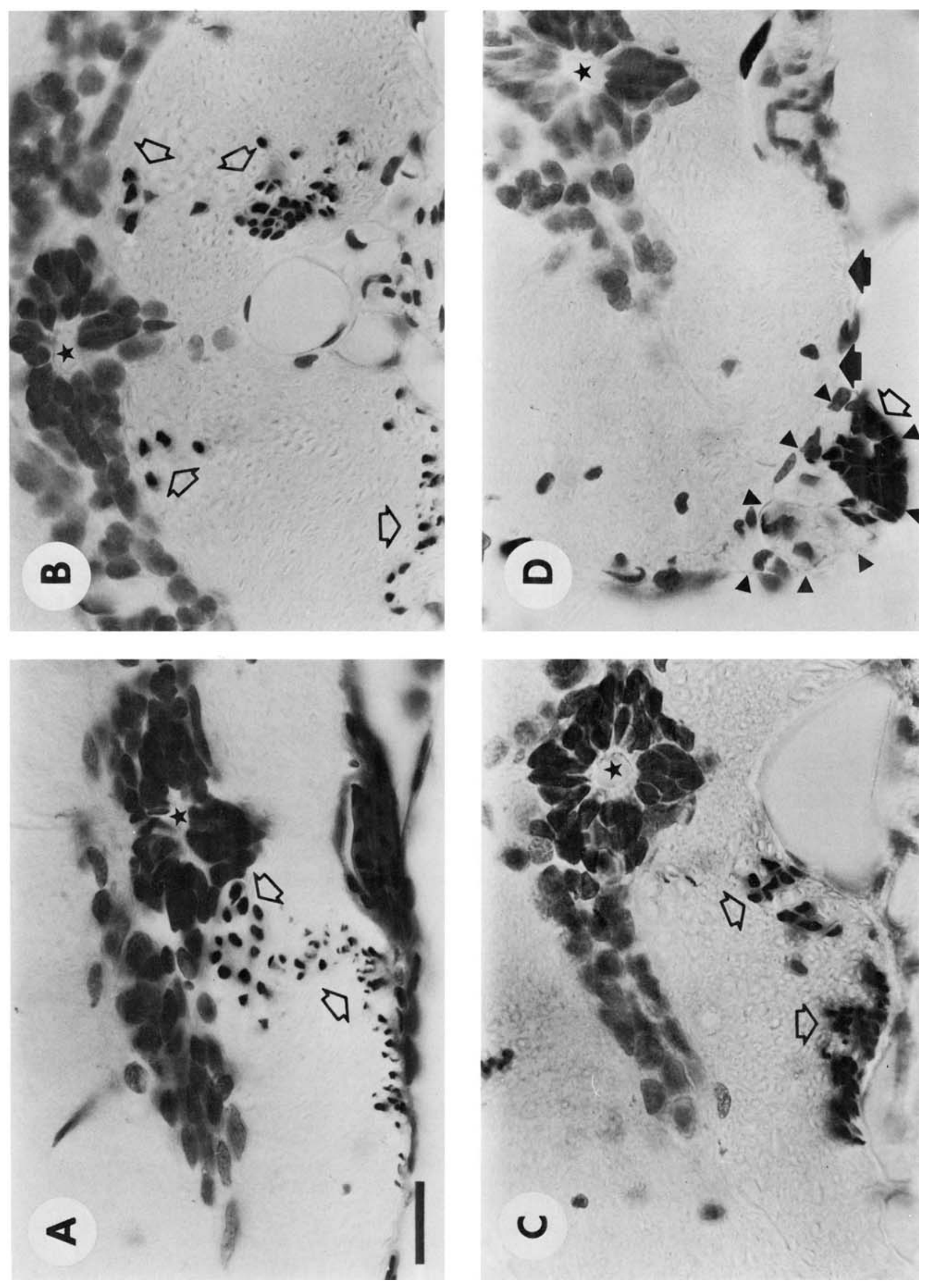

$\overrightarrow{\mathrm{N}}$ 


\section{Somatotopy}

Many motor systems, including the motoneurons innervating (1) the limb muscles in birds and mammals (Landmesser, '78a,b; Hollyday, '80; McHanwell and Biscoe, '81), (2) the visceral arch and pectoral musculature of some teleost fish (Luiten, '76; Morita and Finger, '85; Finger and Kalil, '85), (3) the pectoral fin musculature in a cartilaginous fish (Droge and Leonard, '83), (4) the neck musculature in a turtle (Yeow and Peterson, '86), and (5) the axial muscles in rats (Smith and Hollyday, '83) and snakes (Fetcho, '86) are organized in a topographic manner, with motoneurons that occupy adjacent positions in the motor column innervating muscle from adjacent positions in the developing or the adult musculature. In the medial motor column of rats and snakes this topographic relationship is reflected in the adult, in part, by a spatial segregation of the motoneurons innervating muscles derived from the dorsal and ventral portions of the myotome. The motoneurons innervating the epaxial portion of the myomeres in goldfish are not segregated from those innervating hypaxial musculature. There is no simple correspondence between the dorsoventral position of muscle in the myomeres and the location of the motoneurons innervating that muscle in the mediolateral, dorsoventral, or longitudinal extent of the motor column. Axons from both primary and secondary motoneurons travel in dorsal and ventral rami of spinal nerves and innervate both epaxial and hypaxial muscle. Though motoneurons innervating epaxial and hypaxial muscle are not segregated in the motor column, counts of axons in the major rami indicate that individual motoneurons probably do not project into both epaxial and hypaxial muscle. This suggests that different motoneurons, intermingled within the column, innervate epaxial and hypaxial muscle. A similar arrangement exists in the spinal cord of lampreys, where there is no obvious spatial separation of somata of dorsal and ventral myotomal motoneurons, though there are some differences in the dendritic arbors of the two (Wallen et al., '85). In this respect, the organization of the motoneurons innervating the axial musculature of goldfish and lampreys differs substantially from the organization of motoneurons innervating the axial musculature of rats and snakes (Smith and Hollyday, '83; Fetcho, '86). These differences are considered more fully in the following paper.

In Necturus there is some separation (both rostrocaudally and mediolaterally) of the motoneurons having axons in

\footnotetext{
Fig. 21. HRP-filled axons in the spinal cord of Necturus. All panels show transverse counterstained sections, with a star in the central canal. They are each from different spinal cords. Open arrows show the general locations of HRP-filled axons. A. Axons filled after applying HRP to an entire ventral root located caudal to the section. B. HRP-filled axons on the left side of the section (open arrows) from HRP applied to a branch of the dorsal ramus, and on the right side of the section labeled axons (open arrows) from HRP applied to a branch of the ventral ramus of the same segment on the opposite side of the tail. C. HRP-filled axons in a section more caudal than those in $\mathrm{A}$ or $\mathrm{B}$, but still rostral to the labeled root. The group of large axons (upper arrow) is approaching the ventral surface of the cord in the medial portion of the group of axons destined to exit in the ventral root. D. Labeled axons from the ventral ramus (open arrow), within the ventral root (outlined by arrowheads) just caudal to where the root exited from the spinal cord. No HRP-filled processes are located in the ventral portion of the cord (solid arrows). The HRP-filled axons are confined to one side of the ventral root. The scale bar in panel $\mathrm{A}=50 \mu \mathrm{m}$ and also applies to $\mathrm{B}-\mathrm{D}$.
}

the dorsal and ventral rami of spinal nerves, but the locations of the two populations overlap substantially. The axons of primary and secondary motoneurons in Necturus travel in both rami, as they do in goldfish.

\section{The motor column and the functional subdivision of the axial musculature}

The myomeric musculature of cartilaginous and bony fishes, anuran larvae, and aquatic urodeles is divided into superficial red and deep white portions (Sasaki, '74; Totland, '76a,b; Bone, '78). The histological, biochemical, and functional characteristics of these different portions of the myomeres in fishes have been studied in detail (for reviews see Bone, '78; Johnston, '81). In general, the superficial red muscle is specialized for producing slow, sustained swimming, while the deep white muscle is specialized for fast or burst swimming. Most studies of the anatomy of the locomotor system of anamniotes have concentrated on the axial muscle and the peripheral nervous system. There is very little information about how the functional subdivision of the musculature is accomplished centrally.

Three lines of evidence support the conclusion that some features of the organization of the medial motor column of goldfish are related to the functional subdivision of the axial musculature. First, the size distributions of motor axons in the branches of the ventral root entering the white muscle differ from the size distribution of axons in the branch entering red muscle. Large axons are found only in branches in white muscle. Only small axons are found in the medial ramus, which innervates red muscle. Second, HRP applied to the branches of the ventral root entering white muscle fills a population of large axons and large motoneurons in the cord that are not labeled by HRP applied to the branch entering red muscle. Finally, different populations of motoneurons are filled by HRP applied to red or white muscle. Applications to red muscle fill only relatively small motoneurons located in the ventral portion of the motor column. These motoneurons send their small axons lateral to the M-axon, and most of the axons probably travel to the red muscle in the medial ramus of the spinal nerve. HRP applied to white muscle fills some small motoneurons similar to those innervating red muscle, but also some very large motoneurons, which occupy the dorsal portion of the motor column and are not filled from red muscle. The axons of these large motoneurons (and some of the smaller axons probably innervating white muscle) travel medial to the $\mathrm{M}$-axon along their course to the root. These largest motoneurons have been identified previously (Dia mond, '71; Schnitzlein and Brown, '75), and though nothing was known about their field of innervation in the myomere, Diamond presented evidence that they receive a monosynaptic connection from the $\mathrm{M}$-axon and are the first motoneurons activated during a Mauthner-cell-initiated startle response. These cells correspond to the primary motoneurons discussed earlier; the smaller motoneurons are the secondary ones.

The two other studies of the motoneurons innervating different fiber types in the axial musculature of teleost fish arrived at conclusions somewhat similar to my own. Van Raamsdonk and colleagues (83) used HRP to label the red muscle near the lateral line and the white epaxial muscle in different zebrafish (Brachydanio rerio). The motoneurons innervating red and white muscle were different, as they are in goldfish. However, their account of the distribution of labeled cells suggests a much more complete spatial 


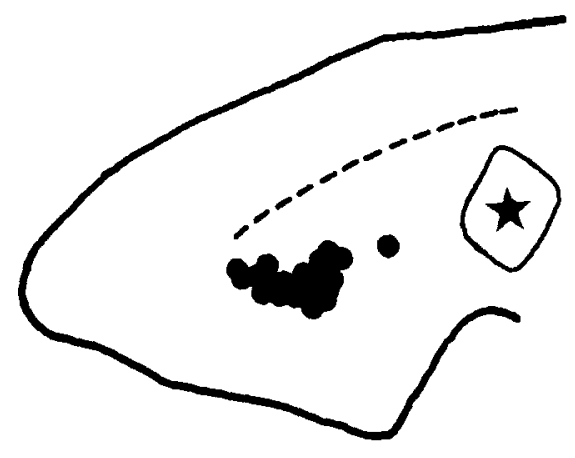

CAUDAL

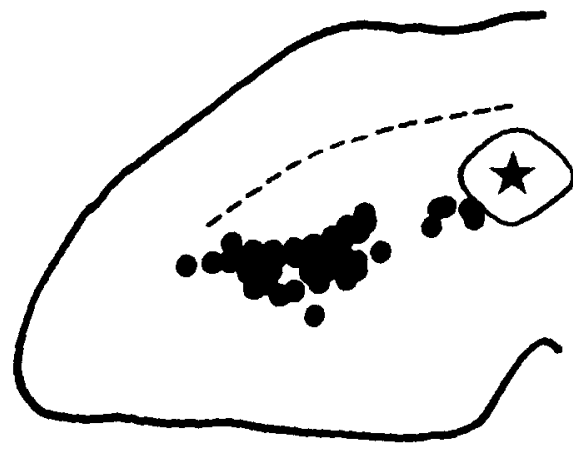

\section{ROSTRAL}

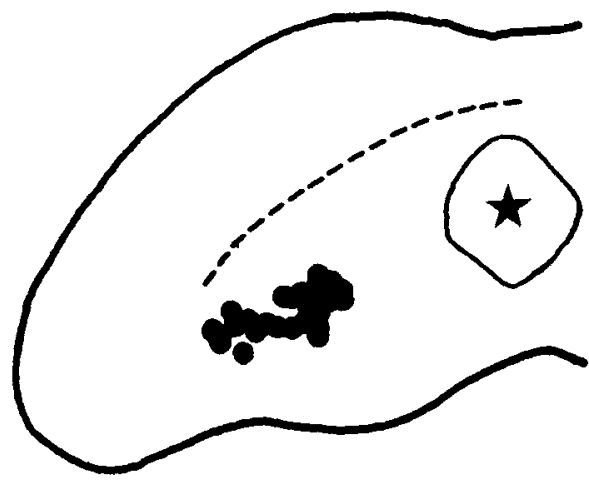

$100 \mathrm{~mm}$

\section{A. Dorsal Ramus}

Fig. 22. Reconstructions of the positions of HRP-filled cells in transverse sections of the spinal cord after applying HRP to (A) a branch of the dorsal ramus or (B) a branch of the ventral ramus of a spinal nerve in Necturus. Two summary sections are represented for each experiment. Each section shows one-half of a transverse section of the cord. On the right in each section a line outlining the ependymal layer surrounds a star marking the central canal. The approximate location of the dorsal portion of the gray matter is indicated by a dashed line. The locations of HRP-filled motoneu-

segregation of red and white motoneurons in zebrafish; motoneurons innervating white muscle were located in only the dorsal portion of the motor column while those innervating red were in its ventral part. Myers ('85) subsequently used HRP to identify the motoneurons innervating white musculature in zebrafish that had not yet developed red muscle. He found labeled motoneurons in both the dorsal and ventral portion of the motor column, not just its dorsal part as in adults (van Raamsdonk et al., '83). His results are consistent with my observations of the motor

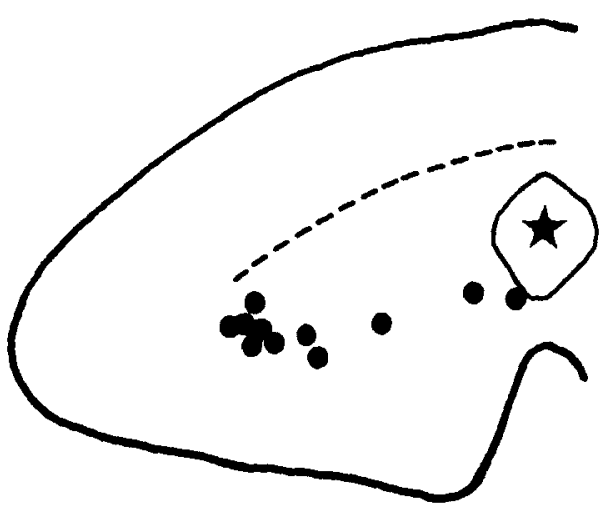

$100 \mu m$

\section{B. Ventral Ramus}

rons are shown as black dots. To produce these summary sections, the number of sections between the most rostral and the most caudal labeled cells in the cord was divided in half. Labeled motoneurons in the rostral half of the sections are plotted on the bottom summary section; those in the caudal half, on the top section. Each section in A represents cells spread longitudinally in the cord over approximately $3.9 \mathrm{~mm}$ and in $B$ approximately $3.7 \mathrm{~mm}$.

column in adult goldfish but are inconsistent with the ob servations by van Raamsdonk et al. ('83), unless some reorganization of the motor column occurs with the development of red muscle.

Though there are some discrepancies among studies of the motor columns in goldfish and zebrafish, in both animals the primary and secondary motoneurons innervate different territories in the myomeres. Primary ones innervate only white muscle while secondary ones innervate both red and white. The primary motoneurons are probably 


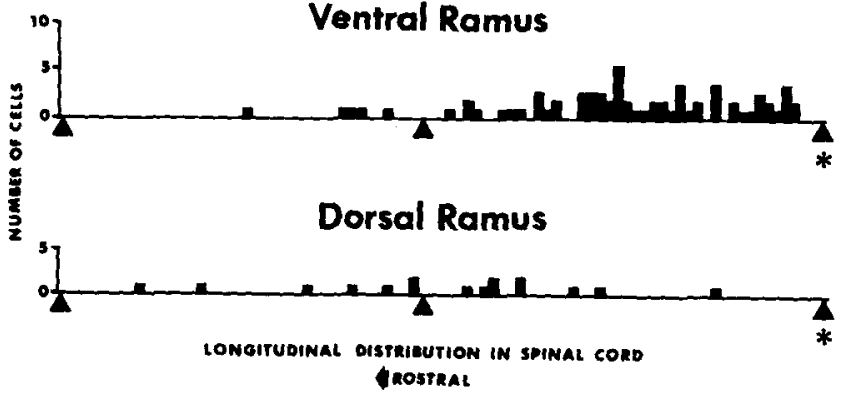

Fig. 23. Longitudinal distribution in the spinal cord of motoneurons filled by HRP applied to the dorsal or ventral ramus in Necturus. A branch of the dorsal ramus was labeled on one side of the tail, and a branch of the ventral ramus of the same segment was labeled on the opposite side. The histograms show the rostrocaudal distribution of labeled cells on each side of the cord. Triangles mark successive ventral roots; the HRP-labeled branch is indicated by an asterisk. Each bin on the histograms represents the number of labeled cells in a distance of approximately $120 \mu \mathrm{m}$ along the longitudinal axis of the cord. No HRP-filled cells were located caudal to the labeled root.

responsible for the important role of the white muscle in rapid acceleration and high-speed locomotion, just as large motoneurons are involved in rapid, forceful movements in other vertebrates (Burke, '81).

The situation in Necturus is less clear. Based on analogy with the organization of the motor system of the goldfish, and previous correlations of the development of motoneurons with the development of motor behaviors in urodeles (Coghill, '13, '26; Blight, '78), the large primary motoneurons in Necturus are probably involved in rapid, forceful movements of the body, while the smaller secondary motoneurons produce slower, weaker ones. Blight ('78) has suggested, based on the trajectories of motor axons in the myomeres of Triturus, that primary and secondary motoneurons may innervate different fiber types; however, his suggestion is difficult to evaluate directly because the very small amount of red muscle in urodeles (Totland, ' $76 \mathrm{a}, \mathrm{b}$; Watanabe et al., ' 80 ) precludes the selective application of HRP to red muscle.

These recent studies are the first efforts to link the organization of the central nervous system of fishes and amphibians to the organization of the axial musculature, and they have revealed some important central correlates of the functional subdivision of the musculature. The populations of motoneurons innervating red and white muscle are clearly different. The white muscle is innervated by a population of motoneurons not innervating red. They are large, they occupy a distinctive position in the dorsal portion of the motor column, and their axon is closely associated with the $\mathrm{M}$-axon in the cord. These motoneurons are not only morphologically different from motoneurons innervating red muscle-they probably also have a different developmental history (Myers, '83). The morphologically similar primary motoneurons in the embryo are the first motoneurons projecting into the axial musculature of zebrafish. Their processes enter the musculature before the growth cone of the $\mathrm{M}$-axon has reached their rostrocaudal position in the cord, and well before any processes of the smaller, more ventral secondary motoneurons reach the periphery (Myers, '83). Thus, differences in morphology and developmental history are correlated with differences in both the field of innervation in the myomeres and the muscle fiber types innervated, and these dissimilarities almost surely reflect the disparate functional roles of primary and secondary motoneurons.

\section{ACKNOWLEDGMENTS}

I thank Dr. Stephen S. Easter, Jr., for his advice throughout the course of this work and for his thorough comments on the manuscript. I also thank Drs. R. Glenn Northcutt, Bruce Oakley, Pamela Raymond, and Steven Scherer for their comments on early versions of the manuscript. Celeste Malinoski helped with the electron microscopy and David Bay helped with the photography. Financial support was provided in part by an NSF predoctoral fellowship, by the Division of Biological Sciences at the University of Michigan, and by NIH grant EY00168 to Dr. S.S. Easter, Jr. This work was submitted in partial fulfillment of the requirements for the Ph.D. in Biological Sciences at the University of Michigan.

\section{LITERATURE CITED}

Adams, J.C. (1977) Technical considerations on the use of horseradish peroxidase. Neuroscience 2:141-146.

Blight, A.R. (1978) Golgi staining of "primary" and "secondary" motoneurons in the developing spinal cord of an amphibian. J. Comp. Neurol. $180: 679-689$.

Bone, Q. (1960) The central nervous system in Amphioxus. J. Comp. Neurol. 115:27-64.

Bone, Q. (1978) Locomotor muscle. In W.S. Hoar and D.J. Randall (eds): Fish Physiology Vol. VII. Locomotion. New York: Academic Press, pp. 361424.

Burke, R.E. (1981) Motor units: Anatomy, physiology and functional organization. In V.B. Brooks (ed): Handbook of Physiology. Section I. The Nervous System. Vol. II. Motor Systems. Washington: American Physiological Society, pp. 345-422.

Carey, F.J. (1983) A dual somatic motor innervation in Urodele Amphibia. Am. Zool. 23:99.

Coghill, G.E. (1913) The primary ventral roots and somatic motor column of Amblystoma. J. Comp. Neurol. 23:121-143.

Coghill, G.E. (1926) Correlated anatomical and physiological studies of the growth of the nervous system in amphibia. VI. The mechanism of integration in Amblystoma punctatum. J. Comp. Neurol. 41:95-152.

Conant, R. (1975) A Field Guide to Reptiles and Amphibians of Eastern and Central North America. Boston: Houghton Mifflin Co.

Davey, D.F., and M.R. Bennett (1982) Variation in the size of release sites along developing and mature motor-terminal branches. Dev. Brain Res. 5:11-22.

Diamond, J. (1971) The mauthner cell. In W.S. Hoar and D.J. Randall (eds): Fish Physiology Vol. V. New York: Academic Press, pp. 265-346.

Droge, M.H., and R.B. Leonard (1983) Organization of spinal motor nuclei in the stingray Dasyatis sabina. Brain Res. 276:201-211.

Eisen, J.S., P.Z. Myers, and M. Westerfield (1984) Segmentally specific growth of motor axons in live zebrafish embryos. Soc. Neuro. Abstr. 10.371.

Farel, P.B., and S.E. Bemelmans (1980) Retrograde labeling of migrating spinal motoneurons in bullfrog larvae. Neurosci. Lett. 18:133-136.

Fetcho, J.R. (1986) The organization of the motoneurons innervating the axial musculature of vertebrates: II. Florida water snakes (Nerodia fasciata pictiventris). J. Comp. Neurol. 249:551-563.

Finger, T.E., and K. Kalil (1985) Organization of motoneuronal pools in the rostral spinal cord of the sea robin, Prionotus carolinus. J. Comp. Neurol. 239:384-390.

Forehand, C.J., and P.B. Farel (1982) Spinal cord development in anuran larvae: I. Primary and secondary neurons. J. Comp. Neurol. 209:386394.

Gasc, J.P. (1981) Axial musculature. In C. Gans and T.S. Parsons (eds): Biology of the Reptilia Vol. 11. New York: Academic Press, pp. 355-435.

Hollyday, M. (1980) Organization of motor pools in the chick lumbar lateral motor column. J. Comp. Neurol. 194:143-170.

Hughes, A. (1959) Studies in embryonic and larval development in amphibia. II. The spinal motor-root. J. Embryol. Exp. Morphol. 7:128-145.

Johnston, I.A. (1981) Structure and function of fish muscles. Symp. Zool. Soc. Lond. 48:71-113. 
Landmesser, L. (1978a) The distribution of motoneurones supplying chick hindlimb muscles. J. Physiol. (Lond.) 284:371-389.

Landmesser, L. (1978b) The development of motor projection patterns in the chick hind limb. J. Physiol. (Lond.) 284:391-414.

Lee, M.T. (1982) Regeneration and functional reconnection of an identified vertebrate central neuron. J. Neurosci. 2:1793-1811.

Luiten, P.G.M. (1976) A somatotopic and functional representation of the respiratory muscles in the trigeminal and facial motor nuclei of the carp (Cyprinus carpio L.). J. Comp Neurol. 166:191-200.

McHanwell, S., and T.J. Biscoe (1981) The localization of motoneurons supplying the hindlimb muscles of the mouse. Philos. Trans. R. Soc. Lond. [Biol.] 293:477-508.

Mesulam, M.M. (1978) Tetramethylbenzidine for horseradish peroxidase neurohistochemistry: A noncarcinogenic blue reaction product with superior sensitivity for visualizing neural afferents and efferents. J. Histochem. Cytochem. 26:106-117.

Moody, S.A., and M.B. Heaton (1981) Morphology of migrating trigemina motor neuroblasts as revealed by horseradish peroxidase retrograde labeling techniques. Neuroscience 6:1701-1723.

Morita, Y., and T.E. Finger (1985) Topographic and laminar organization of the vagal gustatory system in the goldfish, Carassius auratus. J. Comp. Neurol. 238:187-201.

Myers, P.Z. (1983) Morphology and development of motoneurons in the zebrafish spinal cord. Soc. Neurosci. Abstr. 9:848.

Myers, P.Z. (1985) Spinal motoneurons of the larval zebrafish. J. Comp. Neurol. 236:555-561.

Naik, H.T. (1963) Technical variations in Koelle's histochemical method for demonstrating cholinesterase activity. Q. J. Micro. Sci. 104:89-100.

Nishi, S. (1916) Zur vergleichenden Anatomie der eigentlichen (genuinen) Ruckenmuskeln. (Spino-dorsale Muskeln der tetrapoden Wirbeitiere). Gegenbaurs Morphol. Jahrb. 50:167-318.

Nishi, S. (1938) Muskeln des Rumpfes. In L. Bolk, E. Göppert, E. Kallius, and W. Lubosch (eds): Handbuch der vergleichenden Anatomie der Wirbeltiere. Berlin und Wien: Urban \& Schwarzenberg, pp. 351-446.

Nordlander, R.H. (1984) Developing descending neurons of the early Xenopus spinal cord in the caudal spinal cord of early Xenopus. J. Comp. Neurol. 228:117-128.

Raamsdonk, W. van, W. Mos, M.J. Smit-Onel, W.J. van der Laarse, and R. Febres (1983) The development of the spinal motor column in relation to the myotomal muscle fibers in the zebrafish (Brachydanio rerio) I. Posthatching development. Anat. Embryol. 167:125-139.

Roberts, A. and J.D.W. Clarke (1982) The neuroanatomy of an amphibian embryo spinal cord. Philos. Trans. R. Soc. Lond. [Biol.] 296:195-212.
Sarnat, H.B., and M.G. Netsky (1981) Evolution of the Nervous System. New York: Oxford University Press, 504 pp.

Sasaki, F. (1974) Histochemical and ultrastructural studies of tail muscles in the anuran tadpole. Acta Histochem. Cytochem. 7:239-256.

Schnitzlein, H.N., and H.K. Brown (1975) Spinal motoneurons of the gold fish (Carassius auratus). Brain Behav. Evol. 12:207-228.

Smith, C.L., and M. Hollyday (1983) 'The development and postnatal organization of motor nuclei in the rat thoracic spinal cord. J. Comp. Neurol. 220:16-28

Sokal, R.R., and F.J. Rholf (1981) Biometry: The Principles and Practice of Statistics in Biological Research. 2nd. ed. San Francisco: W.H. Freeman and Co., $859 \mathrm{pp}$.

Stephens, N., and N. Holder (1985) A horseradish peroxidase study of motorneuron pools of the forelimb and hindlimb musculature of the axolotl. Proc. R. Soc. Lond. [Biol.] B224:325-339.

Totland, G.K. (1976a) Histological and histochemical studies of segmental muscle in the axolotl (Ambystoma mexicanum Shaw) (Amphibia:Urodela). Now. J. Zool. 24:79-90.

Totland, G.K. (1976b) Three muscle fibre types in the axial muscle of axolot] (Ambystoma mexicanum Shaw) A quantitative light- and electron microscopic study. Cell Tissue Res. 168:65-78.

Wallen, P., S. Grillner, J.L. Feldman, and S. Bergelt (1985) Dorsal and ventral myotome motoneurons and their input during fictive locomotion in lamprey. J. Neurosci. 5:654-661.

Watanabe, K., F. Sasaki, H. Takahama, and H. Iseki (1980) Histogenesis and distribution of red and white muscle fibers of urodelan larvae. J. Anat. 130:83-96.

Whiting, H.P. (1948) Nervous structure of the spinal cord of the young larval brook-lamprey. Q. J. Micro. Sci. 89:359-384.

Yasargil, G.M., and J. Diamond (1968) Startle-response in teleost fish: An elementary circuit for neural discrimination. Nature 220:241-243.

Yeow, M.B.L., and E.H. Peterson (1986) Organization of motor pools supply. ing the cervical musculature in a cryptodyran turtle, Pseudemys scripte elegans. I. Dorsal and ventral motor nuclei of the cervical spinal cord and muscles supplied by a single motor nucleus. J. Comp. Neurol. 243:145-165.

Youngstrom, K.A. (1938) Studies on the developing behavior of Anura. J. Comp. Neurol. 68:351-379.

Youngstrom, K.A. (1940) A primary and a secondary somatic motor inner vation in amblystoma. J. Comp. Neurol. 73:139-151.

Zottoli. S.e. (1978) Comparative morphology of the Mauthner cell in fish and amphibians. In D. Faber and H. Korn (eds): Neurobiology of the Mauthner Cell. New York: Raven Press, pp. 13-45. 